\title{
Resource Interaction in Smallholder Farms is Linked to Farm Sustainability: Evidence from
} Indian Sundarbans

Rupak Goswami ${ }^{1,2,5}$, Sonja Brodt ${ }^{3}$, Sangita Patra ${ }^{1}$, Purnabha Dasgupta ${ }^{1}$, Biswanath Mukherjee ${ }^{4,5}$, Somen Nandi ${ }^{2,5, *}$

${ }^{1}$ Integrated Rural Development and Management Faculty Centre, Ramakrishna Mission Vivekananda Educational and Research Institute, Kolkata 700103, India

${ }^{2}$ Department of Chemical Engineering, University of California, Davis, CA 95616, USA

${ }^{3}$ University of California Sustainable Agriculture Research and Education Program, Davis, CA 95618, USA

${ }^{4}$ Department of Computer Science, University of California, Davis, CA 95616, USA

${ }^{5}$ Global HealthShare ${ }^{\circledR}$ Initiative, University of California, Davis, CA 95616, USA

*For correspondence: snandi@ucdavis.edu

\begin{abstract}
Shrinking farm size and fragile farm resources pose a significant challenge to the sustainability of small-scale farms. Efficient resource utilization in small-scale farms is crucial to achieving farm sustainability through endogenous mechanisms. However, the precise mechanisms to integrate physical resources to achieve farm sustainability are not very clear yet. By capturing the interaction among farm resources as a network phenomenon, we identify the discrete resource interactions (RIs) in different types of small-scale farms of Indian Sundarbans, which are associated with higher farm sustainability. Thirty-two linkages, 11 reciprocal linkages, 22 triads, and three 'core elements' that occurred and cooccurred on highly sustainable farms are found to be critical in achieving farm sustainability. Using the properties of resource interaction networks as explanators of farm sustainability, we anticipate that sustainability in small-scale farms can be achieved by strategically creating new RIs on the farm. However, there may be limitations to such achievement depending on the nature of RI and type of farm. The analytical approach helps to understand the structural basis of sustainability in small-scale farms, and this approach can be used to achieve farm sustainability through the strategic integration of existing farm resources in the smallholder systems.
\end{abstract}

Keywords: resource integration, network analysis, sustainability, small-scale farm. 


\section{Introduction}

Nearly 2.5 billion small-scale farms operate on 60 per cent of the world's arable lands, and their sustainability is critically important to meet the growing demand for food in the coming decades (Cui et al., 2018; Tilman et al., 2011). These farms, across the globe, are typically characterized by resource-poor conditions, vulnerability to biotic and abiotic stresses, climatic variability, and structural constraints (Altieri, Funes-Monzote, \& Petersen, 2012). Achieving sustainability in this large number of small farms will not only play an important role in ensuring global food and nutritional security (Altieri, 2009; Cui et al., 2018; Brunori et al., 2020) but also present a means to secure inclusive economic growth, reduce the vulnerability of rural communities, and rapidly reduce poverty (Pretty, Morison, \& Hine, 2003; Hazell, Poulton, Wiggins, \& Dorward, 2010; Apata et al., 2020). Since small-scale farms often cannot access the same external resources as well-off farms, the existing resources on small farms must be used strategically to move towards sustainability, irrespective of external interventions. Thus, it is crucial to examine how decisions to use a set of physical resources available at any given farm may affect its sustainability status, with particular attention to the extent to which different elements are integrated to maximize the performance of the limited resources available.

The current pandemic due to coronavirus (COVID-19) has far-reaching global economic and environmental implications, with devastating impact on farms across the globe. In developing economies, the pandemic's disruption of the agricultural commodity supply chain has made it difficult for smallholder farmers to find market outlets for their products. Thus, enhancing the resilience of local food systems during this unprecedented pandemic has emerged as crucial for global food security (Bene, 2020). Technology may provide promises of improving conditions for vulnerable farmers even in a period of crisis, such as the ongoing COVID-19 pandemic (Quayson et al., 2020). On the other hand, constrained access to inputs has disrupted farm management and the efficient utilization of farm resources (Stephens et al., 2020).

The speed of exit from smallholder systems remains slow in many developing countries (Hazell, 2011; Hazell \& Rahman, 2014), and increasing population pressure on these systems may lead to resource degradation and reduced efficiency in the long run (Hazell \& Rahman, 2014). Sustainable intensification (SI) in smallholder systems is an approach to ensure continued or increased 
agricultural output while maintaining natural capital (Pretty et al., 2018; Rockstrom et al., 2017; Garnett \& Godfray, 2012). A related term 'ecological intensification' (EI) is used in similar contexts (Bommarco et al., 2013; Tittonell, 2014a; Tittonel \& Giller, 2013) to emphasize a farm's dependence on ecological relationships for intensification of production (Loos et al., 2014). Nevertheless, both SI and EI evoke the idea that productivity and sustainability can be synergistic, rather than merely needing to strike a balance between the two (Pretty et al., 2018; Pretty \& Bharucha, 2014). For the past few decades, examples of sustainable forms of intensification have shown promises in both developed and developing countries (Pretty et al., 2011; Pretty \& Bharucha, 2014), and emerged as alternative ways of farming (Altieri, 1990; Wezel et al., 2014). However, the mechanisms of SI have been summarized only recently (Pretty et al., 2018; Rockstrom et al., 2017; Cassman \& Grassini, 2020), and understanding the pattern to combine existing physical resources as a means of SI remains an outstanding issue.

Sustainable forms of intensification may be achieved by either increasing efficiency, substituting new technologies and practices, or by redesigning the way a system functions (Hill, 1985). It is argued that conscious designing of farming system, often with the introduction of new components and/or processes in it, can be a strategy for smallholder farmers to achieve sustainable livelihoods (Tittonell, 2014b; Goswami et al., 2016). Taking this argument further, we posit that farm families can negotiate multiple factors, internal and external to the farming systems, and consciously design and readjust the farm resources to achieve short- and long-term sustainability. This emphasis on the human agency (i.e., on-farm decision-making) is important since farm families can perceive forces acting on the farm at multiple scales - from field, to landscape/watershed, to market - and experience some degree of latitude in how they choose to utilize available resources to react to these different forces. Although many decisions that affect farm sustainability go well beyond the farm itself (such as institutional innovations and government policy), our study is confined to the scope of farmer decisions about the interaction between resources endogenous to the farm. We will use the term resource interaction (RI) to refer to human-managed material and energy flow, and space sharing between and among different components of a farm such as land, water bodies, livestock, and vegetation. 
A plethora of systems analytic approaches have been developed over the last 30 years in attempts to understand the sustainability of farms and farming systems and to inform development interventions. These approaches include cropping systems models ((Jones et al., 2017; Holzworth et al., 2015; Basso et al., 2016) farming systems approaches that center around farm households and their use of resources (Collinson, 2000; Schut et al., 2015), and agricultural knowledge and information system models that focus on social information flows and decision making (Roling \& Engel, 1991; Hall, Sulaiman, Clark, \& Yoganand, 2003; Temel, Janssen, \& Karimov, 2003; Spielman et al., 2011). Only recently have efforts been made to link sustainable intensification with multiple outcomes in farming systems (Musumba et al., 2018). What has been missing is a way to link the pattern of relationships between different physical resources at the farm level with multidimensional sustainability outcomes. An understanding of how patterns of resource interactions are connected to sustainability will enable development interventions to redesign farms for a better future in low-income economies.

To link resource integrations with farm sustainability, a good starting point is to understand how existing farming systems have evolved over time and endogenously changed their pattern of resource integration as a response to external and internal changes (Cumming et al., 2014). Our understanding of different trajectories of change has a theoretical grounding in the classical economic literature and evolutionary ecology. The economic literature links population dynamics and land constraints to agricultural intensification and suggests that the behavioral response to land scarcity may initiate several trajectories such as resource intensification, shifting of labor to nonfarm activities, and migration, among others (Boderup, 1965; Ruthenberg, 1980). Evolutionary history has also conceptualized organisms within their broader ecological contexts to understand them and predict their behavior (Dunbar, 1989; Smith \& Winterhalder, 2017). We posit that farm typology (Tittonell, 2014b; Tittonell et al., 2010) offers a mechanism for describing different trajectories of farm resource use in an evolutionary context, in the sense that different farm types represent differential resource endowments and different approaches to deploying those resources over time. Ultimately, the farm types that exist in any given region are the outcome of long-term evolution of farming systems in that region, resulting from the interplay of a variety of internal and external factors, including biophysical, economic, cultural, and political realities. This approach is especially pragmatic when we do not have access to comprehensive geo-referenced 
farm survey panel data (Jayne et al., 2014). In this study, however, we delineate farm types based on the structural characteristics and characterize them by several farm-level variables. Farm resource interactions were studied separately (using network analysis) and used to augment the characterization of farm types to give the readers a better understanding of RI occurring in different farm types.

We understand that strategically designing more resilient and sustainable farming systems requires more than simply redesigning RI at the individual farm level. However, our goal here is to focus on the domain of what is immediately accessible to the human agency within the farm household, and which is the pattern of use of existing physical resources. In order to help us to understand which patterns of RI catapult a group of farms to a higher regime of sustainability, we have taken 140 farms of Indian Sundarbans as a use case, whose owners have maintained livelihoods amidst resource crunch, climatic variations, market uncertainties, biotic and abiotic stresses, and geographical isolation. These farms have continuously adjusted their farming systems and livelihoods to cope with these challenges to achieve short- and long-term sustainability. In this article, we delineate farm types in terms of their resource endowment, resource management, and system outcomes. Then, we assess their sustainability and identify the drivers of sustainability in all farm types. We hypothesize that these farm households consciously employ RI in their farms to achieve multiple desirable sustainability outcomes. We examine this relationship of RI with farm sustainability and try to explore what pattern of RI works best for which farm type. Also, we model farm sustainability with the help of network properties of farm resource integration and examine their relationship with different farm types. Further, using a structural model, we explain how sustainability is achieved by using RI in small-scale farms. The study outcomes can identify the discrete RI strategies for different farm types that contribute to higher agricultural sustainability. This will create the basis for the informed and differentiated design of farming systems in developing countries. The analytical approach can also be used elsewhere with situational modifications. To the best of our knowledge, this is a pioneering use of a range of methods to illuminate the role that RI plays in farm sustainability in the context of smallholder agricultural systems. 


\section{Methods}

\section{Sampling and Locations}

The field data were collected from farms of selected areas of Indian Sundarbans, which is constituted of 19 community development blocks (CDB) (Fig. 1). We randomly selected one CDB each from 13 CDBs of South 24 Parganas district and six CDBs of North 24 Parganas District in the West Bengal State of India. From each CDB, one Gram Panchayat (GP) (village self-governing body) was selected randomly. Fifty-two farms from the selected GP of South 24 Parganas and 88 farms from the selected GP of North 24 Parganas - which represent nearly $15 \%$ of the farm families in those GPs - were randomly selected from a list of farms prepared in consultation with the local stakeholders of agricultural development.

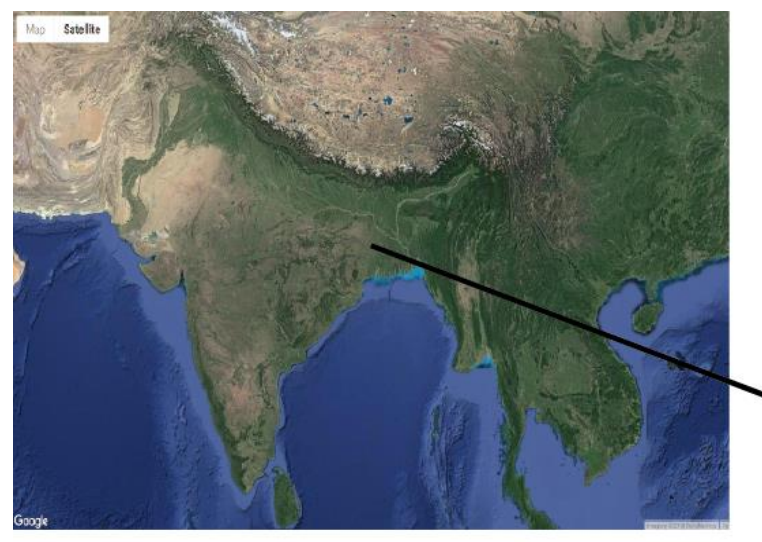

(a)

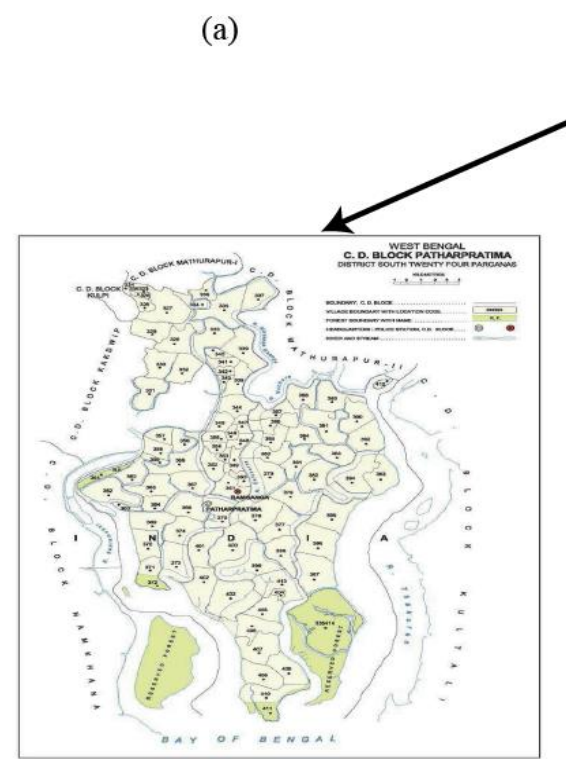

(d)
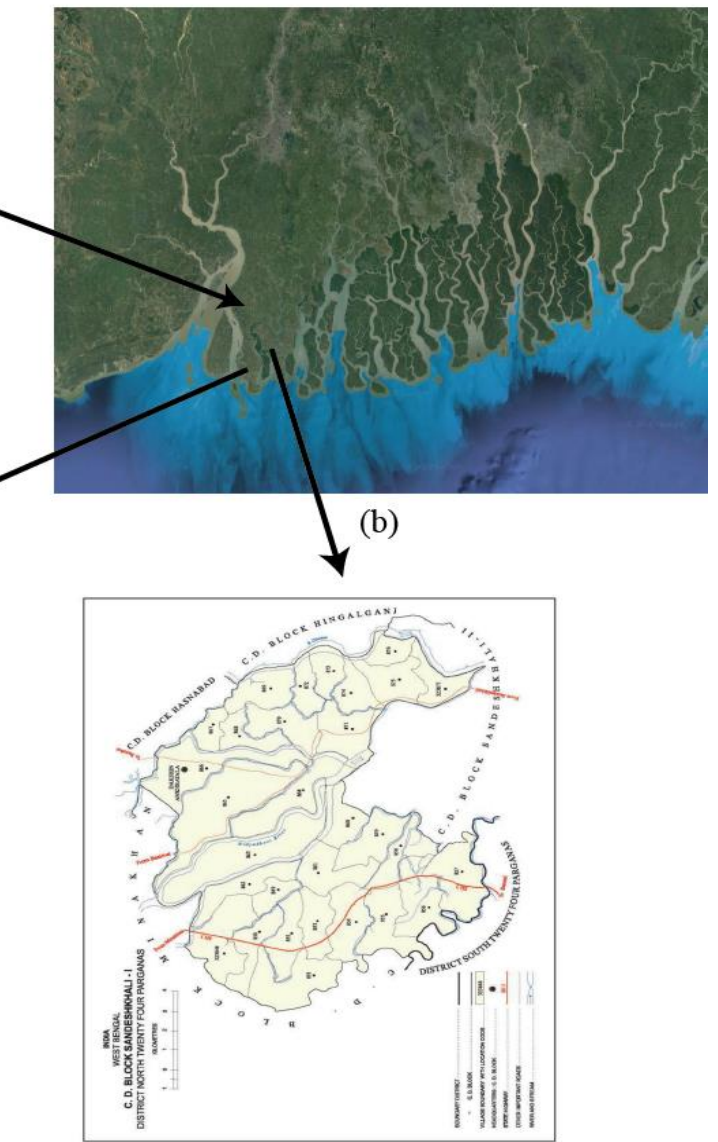

(c)

Fig. 1: Study locations - (a) India; (b) Sundarbans region; (c) Patharpratima Community Development Block; (b) Sandeshkhali-I Community Development Block 
There are six agro-climatic zones - based on climate, soil, and physiography - in the state of West Bengal in India, and the Sundarbans region comes under the coastal saline zone (Gajbhiye and Mandal, 2008). The Indian part of Sundarbans consists of $4200 \mathrm{~km}^{2}$ of reserved forest and 5400 $\mathrm{km}^{2}$ of non-forest areas, and it is intersected by large numbers of rivers, rivulets, and tidal waterways. Fifty-four islands are inhabited by over 4.4 million people (World Bank, 2014). River embankments guard boundaries of islands in the upstream areas, but tidal saline water often intrudes the embankments and floods farmlands. Soil salinity increases in dry months to render the soil uncultivable. The region is vulnerable against cyclonic storms and prolonged inundation. Rice is the main crop grown over different land terrains and seasons. Spring paddy, sesame, and green gram in the early wet season; jute and aman rice in the wet season; and maize, different oilseeds and pulses, and vegetables in the winter season are the important crops. Apart from agriculture, a large portion of the population depends on non-timber forest products, and migrate to urban centers of India and abroad. Population density has risen rapidly over the past decade and is well above the national and state average. Sustainable use of natural resources is critical to managing livelihoods in the region. Nearly half of the population in the region live below the poverty line, and limited employment opportunity creates conflict between livelihoods and environmental sustainability. Nearly all farmers are living marginally, having less than one hectare of land, and sustaining households using small parcels of land within the context of socioeconomic; and environmental vulnerability is a great challenge to support smallholders in Sundarbans.

\section{Data}

Field data were collected through face-to-face interviews with a pre-tested standardized interview schedule (RKMVERI/NDP/EC/RG/Fulb/2018-19) and farm-level measurements. The interview schedule consisted of background information of respondents, different livelihood assets, household income and expenditure, details on farming practices, and resource interaction on the farm. The draft questionnaire was piloted on non-sampled respondents in the study areas and modified based on the experience of piloting. The enumerators stayed in the villages before collection of data, and the actual field data were collected during March-June 2018. Observations and measurements were made on the farms during the interview itself. 


\section{Typology Delineation}

Since the smallholder system is heterogeneous in terms of evolution, resource endowments, and vulnerabilities, the smallholder farmers are expected to employ different strategies of resource intensification and might pursue different trajectories of sustainability outcomes (Tittonnel, 2014b). Different types of farms employ different mechanisms of RI to achieve sustainable livelihoods. Hence, typology delineation for small farms is a pragmatic step to simplify the diverse farming systems before studying the interrelationship of RI and farm sustainability. Based on representative literature (Netting, 1993), we selected 18 potential indicators (Table S1) that could define the smallholder system in the study region. To reduce their multicollinearity, we used principal component analysis (PCA) that resulted in the extraction of six principal components (PCs). These PC scores were then used in hierarchical cluster analysis and K-means cluster analysis to arrive at five distinct farm types. Once we classified the farms based on these six PCs, we characterized them in terms of a set of background variables (Table S2). We tested whether the five farm types differed in terms of this set of background variables. Significant variables in the one-way ANOVA and Chi-square tests suggested the efficacy of our classification. For quantitative variables, we used post-hoc tests after the one-way ANOVA to identify the distinctly high or low farm types for the individual variables. Mostly, these distinct high and low values of indicators were used to characterize different farm types. When the mean value of a variable for a farm type was highest and significantly higher than the other farm types in post-hoc test, we called it 'high'. Similarly, the statistically significant lowest value of a variable was called 'low'. Anything in between was called 'moderate'.

\section{Sustainability Assessment}

For assessing the sustainability of smallholder farms, we followed the relevant frameworks of local and global importance (FAO, 2014; Goswami, Saha, \& Dasgupta, 2017; Rao \& Rogers, 2006). Selection of indicators was guided by the coverage of social, economic, and ecological dimensions of sustainability (Fig. S1), access and availability, cost of measurement, time involved, and understanding of the indicator to the respondents. First, we identified 39 indicators covering social (16), economic (12), and ecological (11) dimensions of sustainability (Table S3). These indicators were standardized, winsorized, weighted, and aggregated to develop a composite sustainability 
index (SI) (OECD, 2008; Goswami et al., 2017). We employed factor loadings of PCs for weighing indicators and aggregated them linearly to develop a composite sustainability index.

\section{Network Data}

Farm families of the study locations identified 10 types of distinct resources/farm components, namely Rice field (R), Vegetable plots (V), Cattle (C), Poultry (PL), Pond (PN), Homestead (H), Tree (T), Kitchen (K), Common property resources (CP), and Fallow land (F) before the actual data collection. We considered the presence of an RI when a perceived flow of energy or matter or sharing of space between any two of these 10 resources existed. We recorded the RIs in a 10x10 binary matrix for all the 140 farms. In graph-theoretic parlance, a node represents the resource/farm component, and a directed tie represents the interaction between two nodes. We generate two types of network information for individual farms: First, we identified the ties, reciprocal ties, triads, and presence of a resource/farm component at the core of the resource interaction network to understand the structural composition of the farm resource interaction. Second, we computed different network properties of individual farms, namely density, component ratio, connectedness, fragmentation, compactness, dependency ratio, Weiner index, closure, transitivity, clustering coefficient, and arc reciprocity, to understand the nature of resource interaction in the farms. Descriptions of the related concepts and terms are listed in Table 1. We used UCINET for Windows software (Borgatti, Everett, \& Freeman, 2002) for matrix manipulation and analyses of the structural composition of the farms, i.e., the ties, reciprocal ties, triads, and presence at the core. We used the same software for the computation of network properties of RI. The structural compositions were then related to farm sustainability and farm types in a graph-theoretic layout using NetDraw software (Borgatti, 2002). NetDraw was also used for the visualization of cooccurrence of RI.

Table 1: Description of key terms and measurements used in the network analysis.

\begin{tabular}{ll}
\hline \multicolumn{1}{c}{ Concepts } & \multicolumn{1}{c}{ Description } \\
\hline Tie/Linkage: & One-way or directed relationship between two farm resources \\
$\begin{array}{l}\text { Reciprocal } \\
\text { tie/linkage: }\end{array}$ & Two-way relationship between two farm resources \\
Triads: & $\begin{array}{l}\text { Three resources linked as a triangle using any of the possible combinations of one and/or } \\
\text { two-way relations. With directed data, there are } 16 \text { possible types of relations among three } \\
\end{array}$ \\
& resources, including relationships showing the hierarchy, equality, and exclusion \\
\hline
\end{tabular}


Core-periphery: $\quad$ Fits a core/periphery model to the data network, and identifies which farm resources belong in the core and which belong in the periphery by employing the algorithm that uses indegree for binary data as a starting partition. A hill-climbing technique is used to improve the initial partitions, and the best fit is reported (Borgatti \& Everett, 2000)

Density In a binary network, density is the sum of the ties divided by the number of possible ties in a network. The value of density ranges between ' 0 ' to ' 1 ', where ' 0 ' represents the absence of tie, and ' 1 ' represents the presence of all possible ties in the network. The possibilities of variation in density measures with sample size are avoided since we use a sample size of 10 (number of farm resources or farm components) for all the farms

Component ratio The ratio of 'one less the number of components in a network' and 'one less the number of nodes in the network'. It ranges between ' 0 ' to ' 1 ', where ' 0 ' represents a single component of the network, and ' 1 ' represents the condition when no node in a network is connected to any other node in the network

Connectedness Connectedness is the proportion of pairs of nodes in a network that are reachable by a path and Fragmentation of any length. Fragmentation is defined as the reciprocal of Connectedness.

Compactness

Compactness is the mean of all the reciprocal distances between the nodes in a network. It has a value of 1 when all the nodes in a network are adjacent (clique) and 0 when no node in the network is connected to others (isolate).

Dependency ratio The proportion of pairs of nodes that are unreachable in a network

Weiner Index Sum of the geodesic distances between all pairs of nodes in a network.

Closure

The number of non-vacuous transitive triples divided by the number of paths of length 2

Transitivity

Three vertices $a, b, c$ taken from a directed graph are transitive if whenever vertex $a$ is connected to vertex $b$ and vertex $b$ is connected to vertex $c$, then vertex $a$ is connected to vertex $c$. It is measured by the number of triples that are transitive, divided by the number of triples, which may be converted into transitive by the addition of a single edge

Clustering

coefficient

The clustering coefficient of a graph is the average of the densities of the neighbourhoods of all its nodes. First, the densities of ties for all nodes are computed, and then they are averaged.

Arc reciprocity The number of reciprocated arcs (directed edges) divided by the total number of arcs in a network.

Adapted from Borgatti, Everett, \& Johnson (2018)

\section{Model Development}

We examined the relationship between farm resource interaction and farm sustainability through two approaches. First, we used two extracted principal components from 11 network properties of 140 farms to explain their sustainability score. Using SPSS Modeler 18.1 (IBM Corp., 2016), we employed 12 models together, and the output is based on three best-performing models based on 
their correlation value and relative error (Table S4, Supplementary Information). The relationship was also examined separately for all five farm types to examine whether it held across farm types.

\section{Results}

\section{Typology Delineation}

Farm typology delineation is a cross-cutting task undertaken before the analysis of natural resource management in any region (Tittonell et al., 2010). It significantly reduces the heterogeneity of smallholder systems and creates socio-ecological boundaries within which resource management can be better understood (Tittonell et al., 2005; Kansiime, van Asten, \& Sneyers, 2018). For typology delineation, we used a sequence of principal component analysis (PCA) and hierarchical cluster analysis (CA). Variables used in PCA are given as supplementary information (Table S1). PCA reduced collinearity of the dataset and extracted six principal components, and CA clustered the farms by using the extracted PCs (Fig S2). Analysis of data on 140 farms suggested five distinct farm types (Fig. 2). The farm types were characterized by several farm-level variables (Table S2, Supplementary Information). When the mean value of a variable or a set of variables for a farm type is highest and significantly higher than the other farm types in the post-hoc test, we call it/them 'high'. Similarly, the lowest value of a variable/set of variables was/were called 'low'. Anything in between was considered 'moderate'. A qualitative description of farm types is given as Supplementary Information (Row 1, Table S4). 


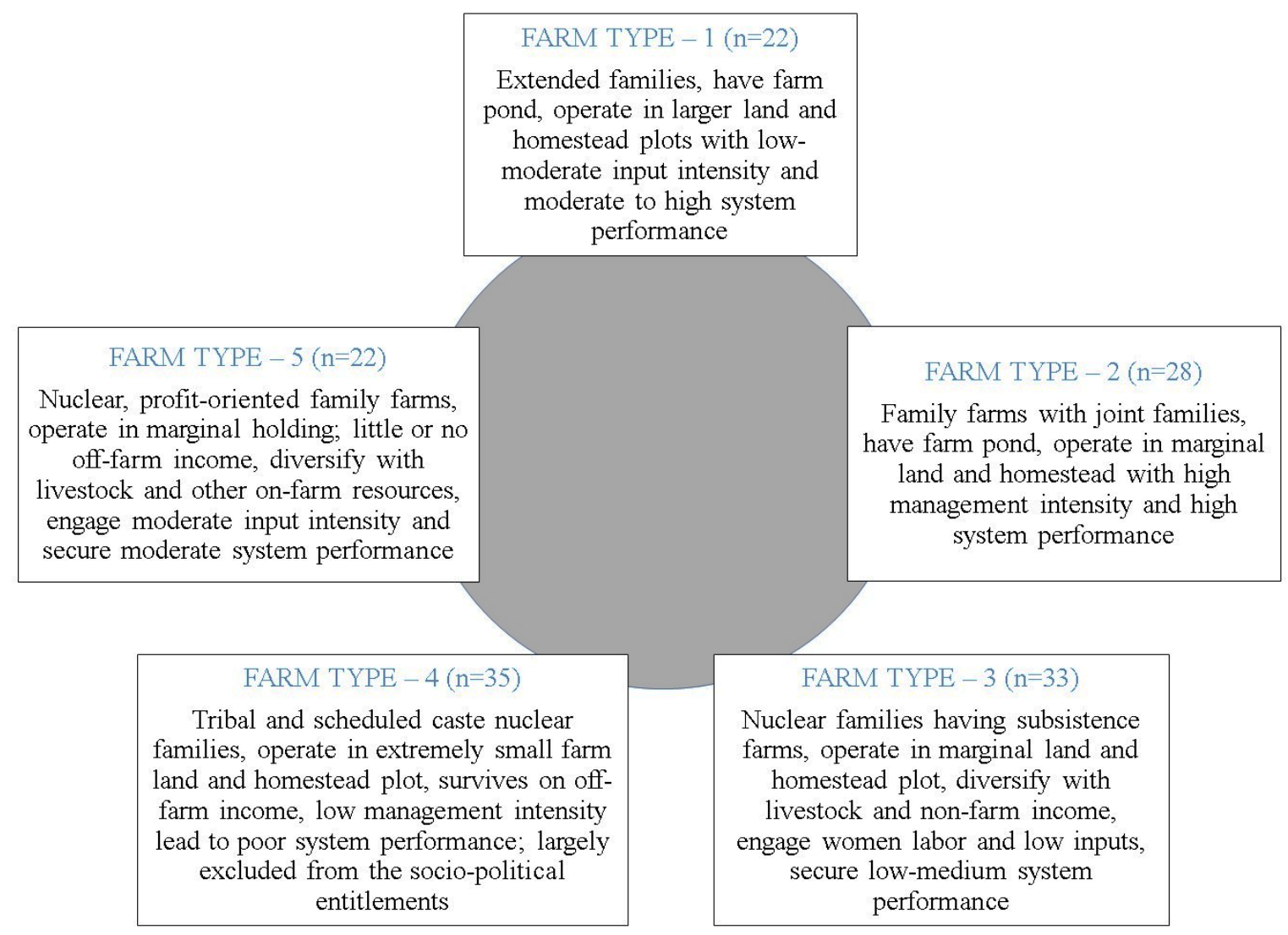

Fig. 2: Qualitative description of five farm types. The description is based on a One-Way ANOVA ran with a set of variables across five farm types. Variables or set of variables having statistically significant high or low values (in post-hoc test) for a farm type were used for its description. System performance denotes system productivity and profitability

Farm type-1 ( $15.71 \%$ of farms) were resource-rich extended families, who employed low-tomoderate input intensity and demonstrated moderate-to-high system yield and system profitability in their farms. Farm type-2 (20\% of farms) were resource-poor extended families, who achieved high system yield by employing high input intensity and family labor. Farm type-3 (23.57\% of farms) were resource-poor feminized subsistence farms that diversified with livestock and nonfarm incomes, used low input intensity in farming, and received moderate system yield and low system profitability. Farm type-4 (25\% of farms) was predominated by resource-poor and marginalized tribal nuclear families, who survived on off-farm wages, used low input-intensity on their farms, and achieved moderate system yield and low system profitability. Farm type-5 ( $15.71 \%$ of farms) was resource-poor, profit-oriented nuclear families, which diversified with 
livestock, earned little or no off-farm income and employed moderate management intensity to maintain moderate system yield and profitability.

\section{Farm Sustainability and Its Drivers in the Study Areas}

Sustainability measured by a comprehensive and valid set of indicators, based on a sound theoretical framework, can give an idea of the overall status of a farm (Gibson, 2006; GómezLimón, \& Sanchez-Fernandez, 2010). When social, economic, and ecological dimensions are adequately measured by valid means, we approximate a farm's ecological state, economic performance, and social outcomes together, often in the form of composite indices (Diaz-Balteiro, González-Pachón, \& Romero, 2017). At the first stage of our analyses, we assessed the sustainability of 140 farms by a composite index built on 39 indicators covering social, economic, and ecological dimensions of sustainability (Table 1). 


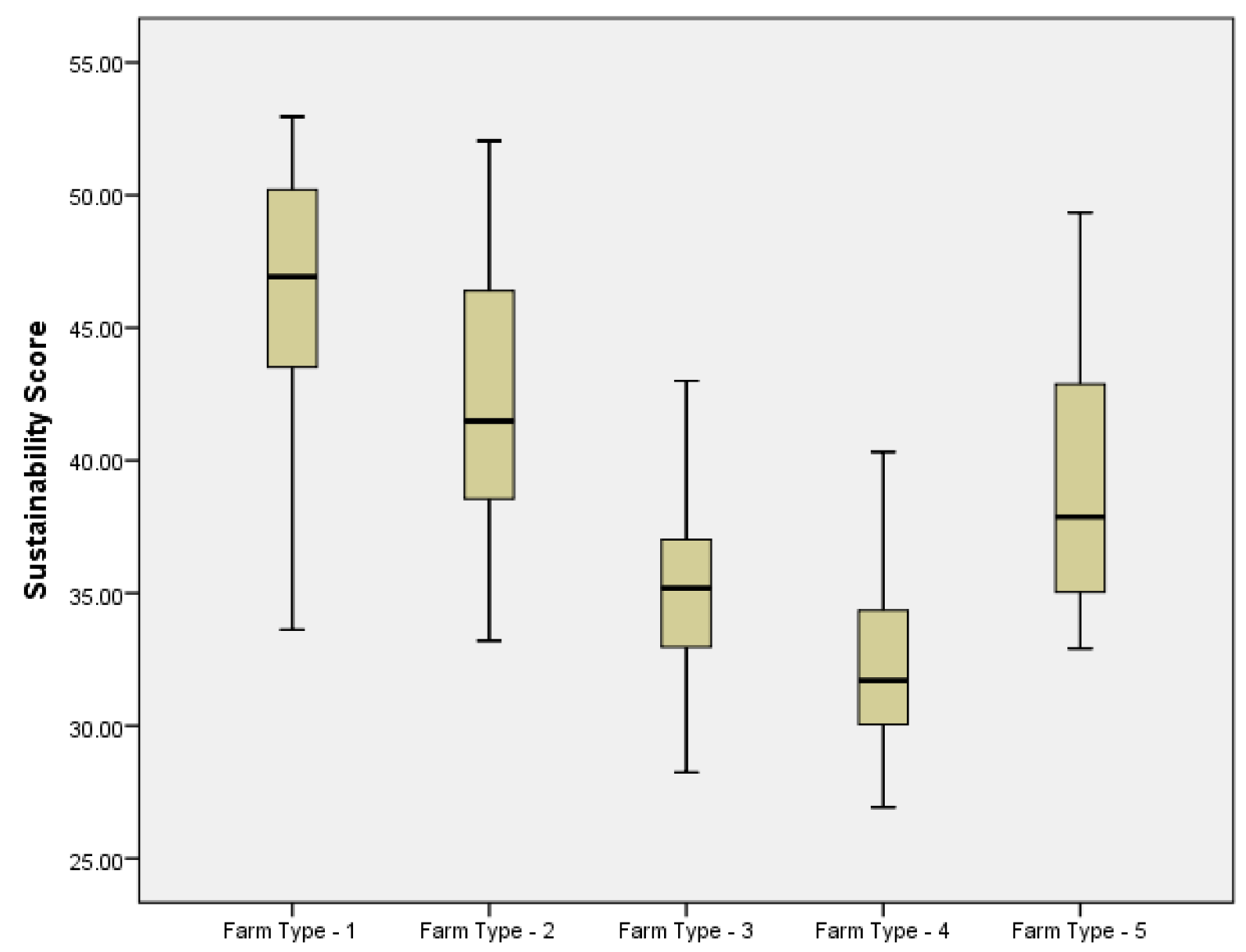

Fig 3: Sustainability score of farms under five farm types. Sustainability is assessed by a composite sustainability index developed from 39 indicators (Table 1). The indicators are normalized, winsored, weighted and linearly aggregated to develop the composite index

The mean sustainability score for FT-1 was highest, followed by that of FT-2, FT-5, FT-3, and FT4 (Fig. 3). The resource-rich large families (FT-1) fared better than other farms in terms of multifunctionality, balanced soil reaction, contact with extension functionaries, lower cost of production, availability of cereals, and adoption of sustainable agricultural practices (Fig. 4). The intensive and extensive marginal cultivators (FT-2) closely followed FT-1 in all the above indicators. Also, they came next to highest in terms of women's engagement as family labor, family dependency ratio, women's access to farm resources, use of family labor in farming, lesser soil salinity, tree species diversity, per-capita income, the proportion of irrigated land, system profitability, use of organic manure, and rice equivalent yield. The diversified, profit-oriented farms (FT-5) followed FT-1 or FT-2 in terms of several indicators and emerged next to highest in livestock index and distance to the road. The migrant and feminized farms (FT-3) fared best in 
terms of Nitrogen, Phosphorus, Potassium (NPK) use and pesticide use, distance to market, access to financial institutions, use of indigenous knowledge and per-capita food availability, apart from being second best in terms of livestock index, training, availability of cereals, and soil fertility. income diversity and soil fertility and emerged second best in terms of distance to market, NPK use, pesticide use, and use of indigenous knowledge.

However, to understand the distribution of sustainability scores and their constituent indicators under individual farm type, it is crucial to examine the - a) performance of all farms within a farm type in terms of composite sustainability score; and b) performance of individual farms of a farm type across all indicators. This could provide an idea about the stability of a farm type (less variance of sustainability score), and their characteristics may be defined by a set of stable constituent indicators (having less variance within a farm type). The interquartile range of highlysustainable farm types was wider than that of less-sustainable farm types, indicating a higher variability among the highly-sustainable farm types (Fig. 3). Interestingly, inter-indicator variation, measured by the average coefficient of variation of 39 sustainability indicators, was highest in FT-2 (75.02\%), followed by FT-5 (72.08\%), FT-4 (62.25\%), FT-1 (59.2\%), and FT-3 $(53.81 \%)$, indicating the more consistent performance of FT-3 and FT-1 across indicators (Fig. 4). They may be considered as a group of farms which are in a relatively more stable sustainability regime, which may not necessarily be highly sustainable. We can also find the most skewed indicators for individual farm types Overall, 'training', 'ownership of pond', and 'irrigation by preserved water' are the most skewed indicators across farm types. We suggest that the sustainability of a farm type is characterized by the indicators having high mean value and less variance, representing a more stable state. Hence, description of farm types in terms of stable sustainability indicators might add value to our earlier characterization of farm types and be considered as the extension of our typological delineation of farms (Row 2, Table S5; Supplementary Information). A scheme is conceptualized to show sustainability regimes of different farm types concerning their assets and capabilities for a better comprehension of the readers (Fig. S3) 


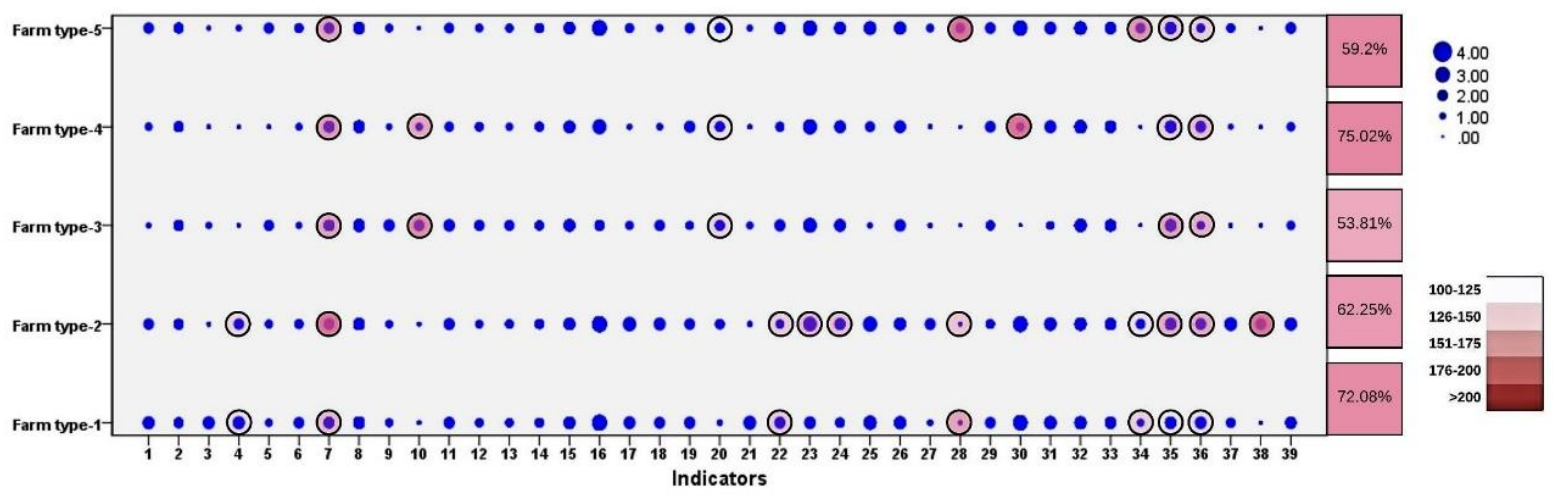

Fig. 4: Performance of different farm types in terms of 39 sustainability indicators. Indicator scores are standardized weighted values. Circles are scaled by indicator score. Encircled dots have higher variability $(>100 \% \mathrm{CV})$ within a farm type, and the deeper colors represent higher variability. Boxes at the extreme right show indicator-level variation (average CV\% of 39 indicators), deeper colors being more variable. Larger dots, which are not encircled, are considered to be more stable and used for characterizing farm types.

Indicator code: 1-Experience of farming, 2-Family dependency ratio, 3-Land holding, 4Homestead land, 5-Livestock index, 6-Social participation, 7-Training, 8-Availability of cereals, 9-Dietary diversity, 10-Per-capita food grain, 11-Women's access to farm resource, 12-Use of indigenous knowledge, 13-Pride of being a farmer, 14-Use of family labor in farming, 15Gendered use of family labor, 16-Multifunctionality of farming, 17-Total income, 18-Per-capita income, 19-Income diversity, 20-Proportion of irrigated land, 21-Cultivated land, 22-Access to financial institutions, 23-Distance to market, 24-Distance to road, 25-Extension contact, 26System cost of cultivation, 27-System profitability, 28-Investment in farm, 29-Soil fertility, 30Soil reaction, 31-Soil salinity, 32-NPK use, 33-Pesticide use, 34-Organic manure use, 35Ownership of pond, 36-Irrigation by preserved water, 37-Tree species diversity, 38-Rice Equivalent Yield (REY), 39-Adoption of good agricultural practices

\section{Farm Resource Interaction}

After the delineation of farm typology and understanding their drivers of sustainability, we want to understand the nature of farm resource interaction within each farm type. We examine the abundance of four types of interactions (linkage, reciprocal linkage, triad, and presence at the core) in five identified farm types (Fig. 5) to characterize them in terms of these interactions. The heatmaps represent the proportion of farms under individual farm type having the above-stated four types of RI. Both FT-1 and FT-2 are characterized by R-, H-, and V-based linkages, R-based reciprocal linkages, $\mathrm{R}$ - and V-based triads, and presence of $\mathrm{R}$ and $\mathrm{V}(\mathrm{R}, \mathrm{V}$, and $\mathrm{C}$ for FT-2) at the core of RI network (Row 3, Table S5). Although the abundance of RI is similar in FT-1 and FT-2, the difference primarily exists in the magnitude of their abundance. Also, in FT-2, the importance 
of $\mathrm{C}$ and use of CP and F are unique. Unlike FT-1 and FT-2, FT-3 is characterized by linkages involving diverse resources such as R, H, V, PL, PN, and C; predominantly H, PL, PN, and Vbased reciprocal linkages; R, V, PN, PL, and H-based triads; and the presence of $\mathrm{H}$ and V at the core of the RI networks. FT-4 shows the presence of fewer linkages, reciprocal linages, triads; and features the presence of $\mathrm{H}$ at the core of the networks. FT-5 is characterized by a smaller number of diverse linkages involving $\mathrm{R}, \mathrm{H}$, and $\mathrm{C}$; very few reciprocal linkages and triads; and presence of R, V, and C at the core of the RI networks. Overall, FT-1 and FT-2 employed similar resource integration strategies centering around $\mathrm{R}, \mathrm{H}$, and V, with FT-2 integrating $\mathrm{C}$ and V slightly more than the FT-1; and FT-3 used diverse resources for interaction - centering around $\mathrm{H}$ - that could spatially accommodate V, PN, PL, C, and K due to their physical proximity. For FT-4, the paucity of resources and dependence on off-farm income might have resulted in a lack of resource interaction on their farms. FT-5, on the other hand, showed a diverse but non-predominant nature of resource interactions centering $\mathrm{R}, \mathrm{H}$, and $\mathrm{C}$. We now extend our typology characterization further in terms of their fundamental characteristics, their drivers of sustainability, and predominant resource interaction pattern on the farm (Row 3, Table S4; Supplementary Information). 


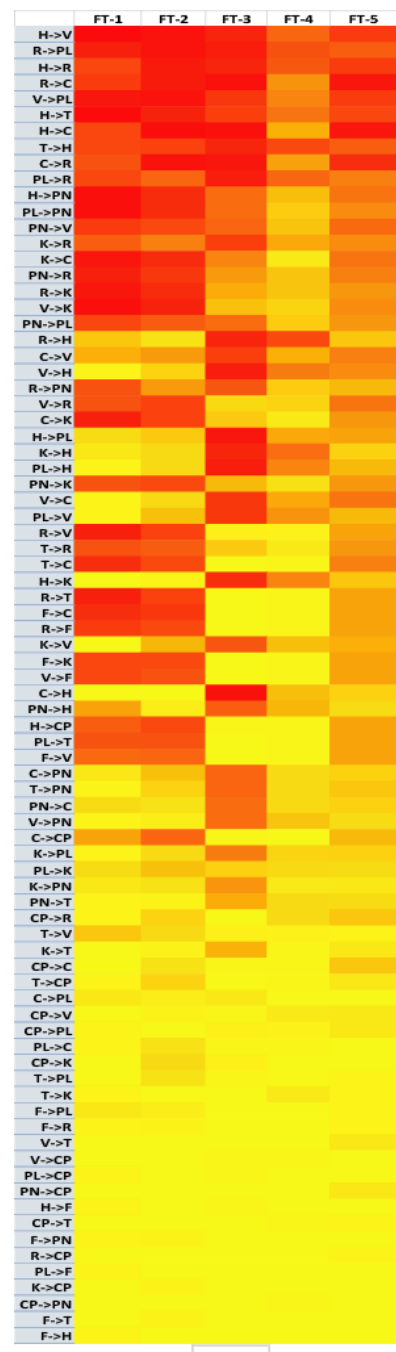

(a)

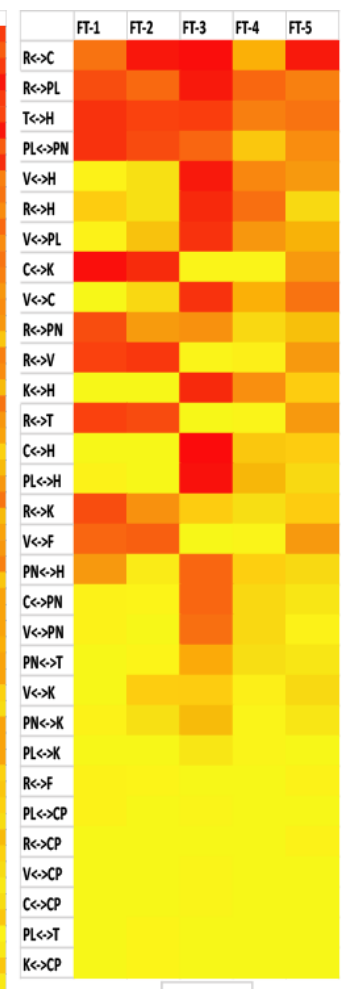

(b)

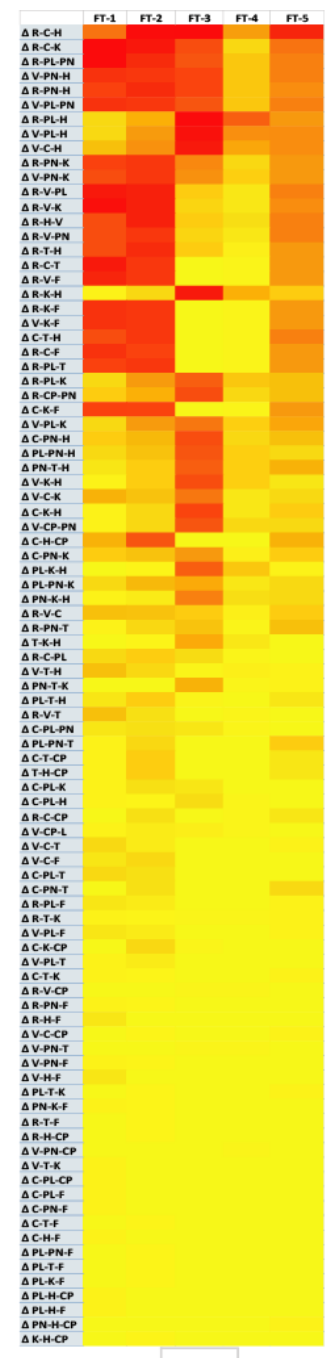

(c)

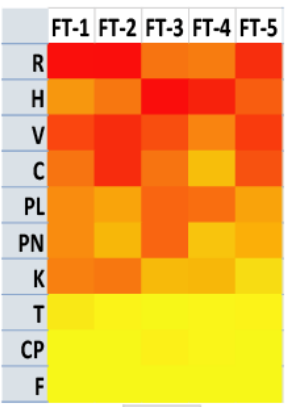

(d)

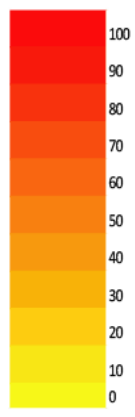

Fig. 5: Abundance of different types of resource interaction across farm types - a) Tie/linkage; b) Reciprocal tie/linkage; c) Triad; and d) Presence in the core. Abundance indicates the percentage of farms having a type of resource interaction within a given farm type.

\section{Farm Resource Interaction vis-à-vis Farm Sustainability}

Once the farm types are characterized by their sustainability scores and resource interaction patterns, we inquire how these resource interaction patterns might be related to their sustainability. The highly-sustainable farms, mostly from FT-1, FT-2, and a few from FT-5, are clustered at the left-bottom part of the figure and are associated with 34 RIs, involving mostly R (13), followed by C (8), V (7), K (7), PN (7), H (7), T (6), and PL (5) based linkages (Fig. 6a; Row 3, Table S5). On the other hand, less-sustainable farms, mostly from FT-3 and FT-4, are clustered at the upper-right part of the figure, which are associated with PL- and H-based linkages. Some farms from FT-3, 
FT-4, and FT-5 are scattered at the bottom right and are related to the linkages CP->R. The twomode network for the reciprocal linkages features highly-sustainable farms (FT-1, FT-2, and a few from FT-5) at the upper half of the figure (Fig. 6b), less-sustainable farms (FT-3 and FT-4) at the middle, and moderately-sustainable farms at the bottom (mostly from FT-5). Highly-sustainable farms are predominantly associated with R-based reciprocal linkages with a few V-, K-, and PNbased linkages; moderately-sustainable farms are associated with few R-and PN-based reciprocal linkages, and poorly-sustainable farms with H- and V-based reciprocal linkages. In Fig. 6c, highlysustainable farms are clustered at the left part of the figure with a division between the upper and lower parts. Where the highly-sustainable farms (FT-1 and FT-2) are associated with R-, V-, PN, K-, and H-based triads, the poorly-sustainable farms (FT-3 and FT-4) are associated with H-, K, V-, C-, PL- and PN-based triads. Farms of FT-5 are scattered across the figure, implying differential sustainability of the farms and their employment of diverse resource interaction strategies. Highly-sustainable farms (mostly FT-1 and FT-2) were mostly associated with the occurrence of R and C, or K at the core of the network (Fig. 6d). The occurrence of V and PN at the core were found in both high (mostly FT-1 and FT-2) and moderately-sustainable (mostly FT5) farms; while PL and H were found at the core of low (mostly FT-3 and FT-4) and moderately sustainable (mostly FT-5) farms. In summary, farms achieve higher sustainability by having R-, V, C-, PN-, H-, and K-based linkages; R-based reciprocal linkages; R-, V-, PN-, K-, and H-based triads; and presence of $\mathrm{R}, \mathrm{C}$, and $\mathrm{K}$ at the core. However, resource interaction associated with one kind of resource could not be exclusively attributed to farms having higher sustainability. 


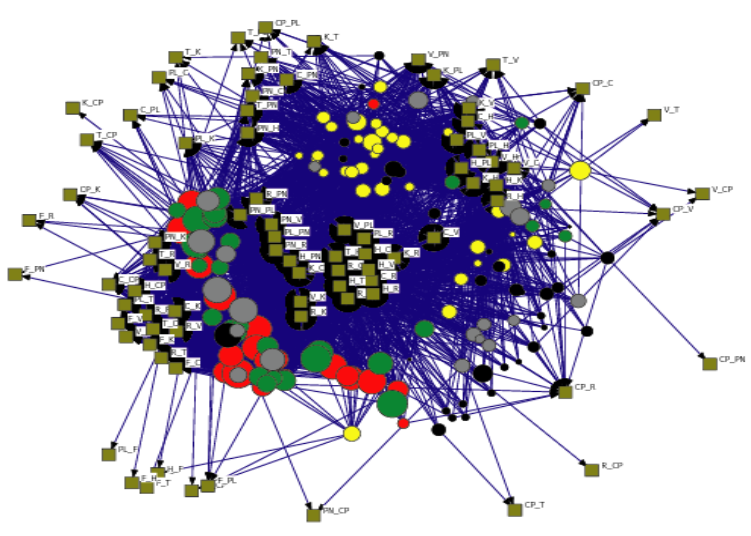

(a)

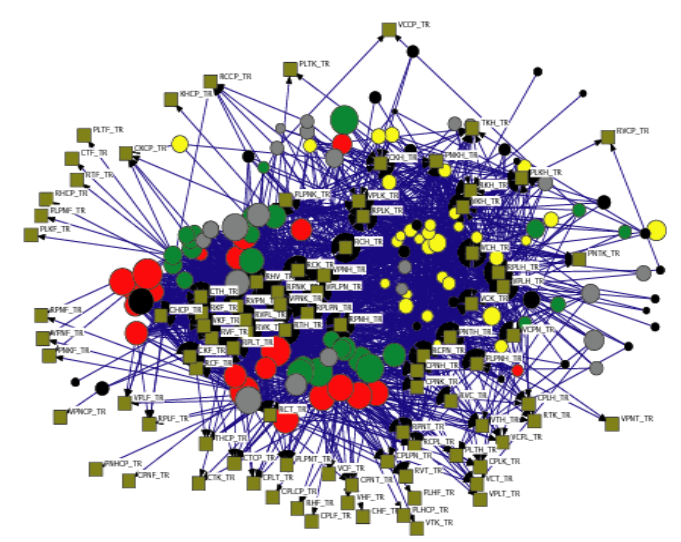

(c)

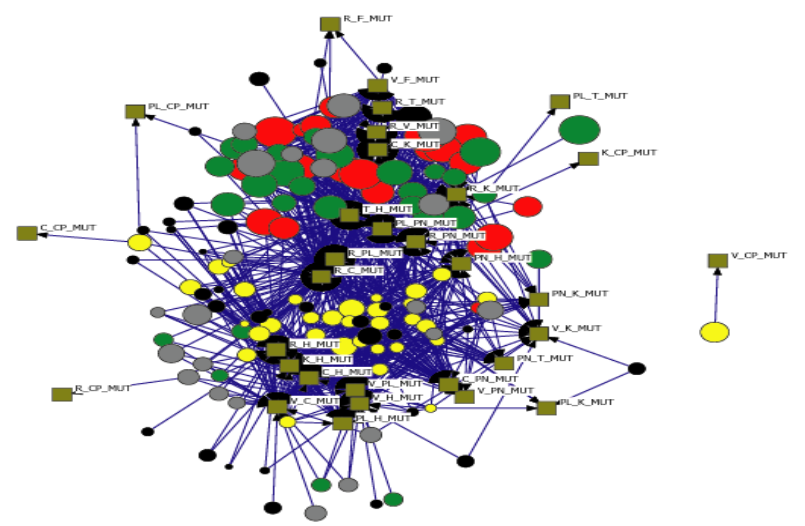

(b)

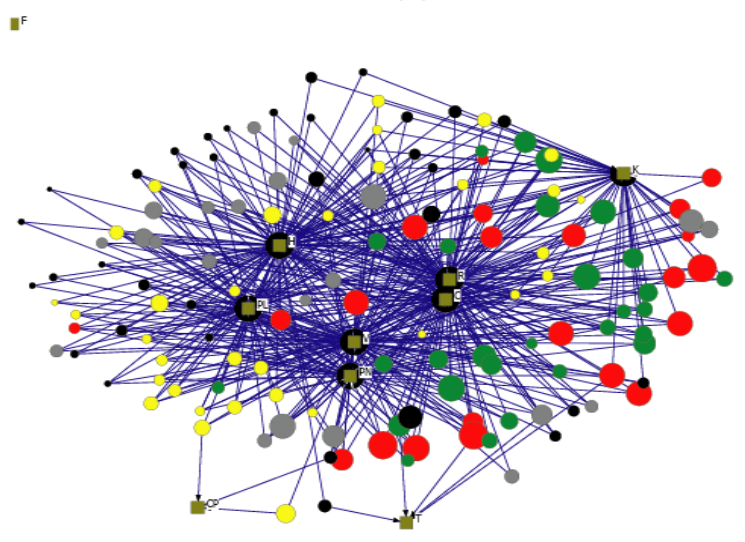

(d)

Fig. 6: Relationship between occurrence of different types of resource interaction (RI) (boxes) with farm sustainability of different farm types (FT). Four types of RI are - (a) Tie/linkage; (b) Reciprocal ties/linkage; (c) Triads; and (d) Presence in the Core. Sizes of circles are proportional to farm sustainability scores; colors represent different types of farm. The closeness of boxes and circles in the graph-theoretic layout denotes higher tie strength between farms and RI. Resource code: Rice field (R), Vegetable plots (V), Cattle (C), Poultry (PL), Pond (PN), Homestead (H), Tree (T), Kitchen (K), Common property resources (CP), and Fallow land (F). Color scheme of nodes: FT 1 - Red; FT 2 - Green; FT 3 - Yellow; FT 4 - Black; FT 5 - Grey. Nodes are moved minimally to make the labels legible

Please note that, while Fig. 5 describes farm types by the abundance of RIs for individual farm types, Fig. 6 associate individual RI to one or the other farm types of higher and lower sustainability scores. Hence, we can more conclusively claim that higher sustainability was achieved by a given set of RI in individual farm types. Further, scrutiny of the farms in the ninth decile of sustainability score provided a hint of how highest sustainability was achieved, irrespective of farm types, by using specific resource interactions and not others (Fig. 7; Row 2, Table 3). Confirmatory scrutiny of both sets of Fig. 6 and Fig. 7 shows that a high proportion of 
RI linkages associated with sustainable farms also feature in those of the farms of the highest decile of sustainability score.

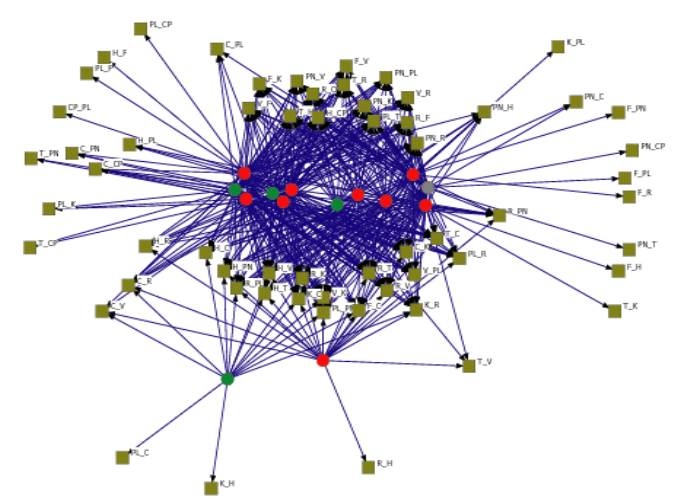

(a)

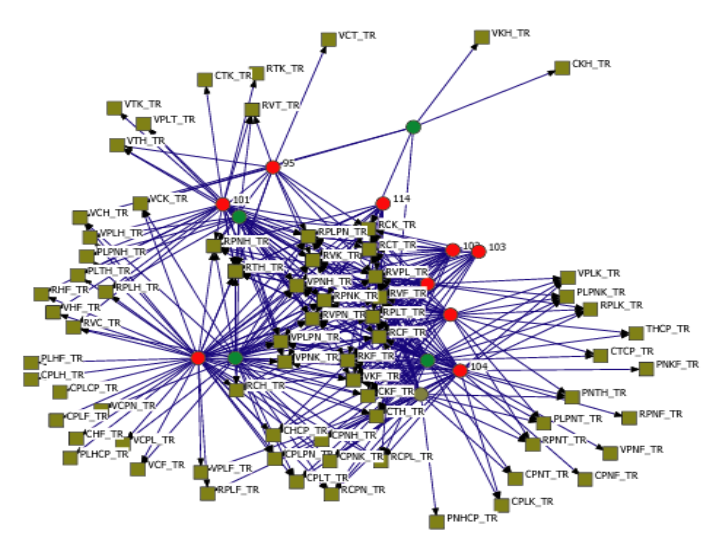

(c)

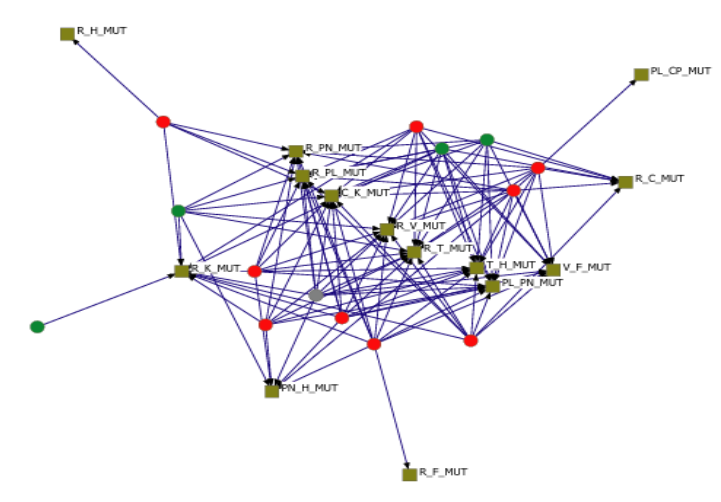

(b)

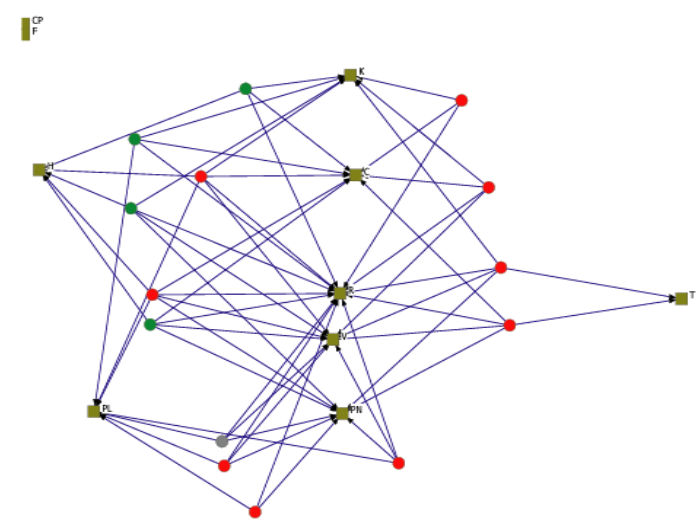

(d)

Fig. 7: Relationship between occurrence of different types of resource interaction (RI) (boxes) with farm sustainability among the farms of ninth decile (of farm sustainability score). Four types of RI are - (a) Tie/linkage; (b) Reciprocal ties/linkage; (c) Triads; and (d) Presence in the Core. Closeness of boxes and circles in the graph-theoretic layout denotes higher tie strength between farms and RI. Color scheme of nodes: FT 1 - Red; FT 2 - Green; FT 5 - Grey. No farms from FT4 and FT-5 featured in the figures. Nodes are moved minimally to make the labels legible

\section{Co-occurrence of Farm Resource Interaction}

Apart from studying the occurrence of RI, we wanted to study the pattern of co-occurrence of RI (on the same farm) in different farm types. Note that co-occurrence means the simultaneous occurrence of RIs on the same farm. Co-occurrence study was performed for two reasons - first, the co-occurrence of resource interaction on a farm is expected to be more stable because of its possible interdependence on a farm. Hence, studying them gives us an idea of what RIs go together 
and stabilize in smallholder systems of a region as a response to the internal and external stimulus of change to the farming systems. Second, in the absence of panel data on farm RI or empirical study on the evolution of regional farming systems, the study of co-occurrence of RI could suggest the possible evolutionary pathway of sustainability in a smallholder system at a given point of time. Despite the limitation of snapshot data, we can examine how these co-occurrence patterns of RI accumulated in highly-sustainable farms. We studied co-occurrence of the four types of RI by converting the two-mode matrix of 'farm vs resource interaction' into a one-mode matrix of 'resource vs resource'. The network of co-occurrence for all 140 farms together gave us an idea of 'generic' RI patterns for the study area. We segregated the co-occurrence of RIs for farms of the ninth decile in terms of their sustainability scores to understand their variation from the 'generic' network (Fig. 8). 

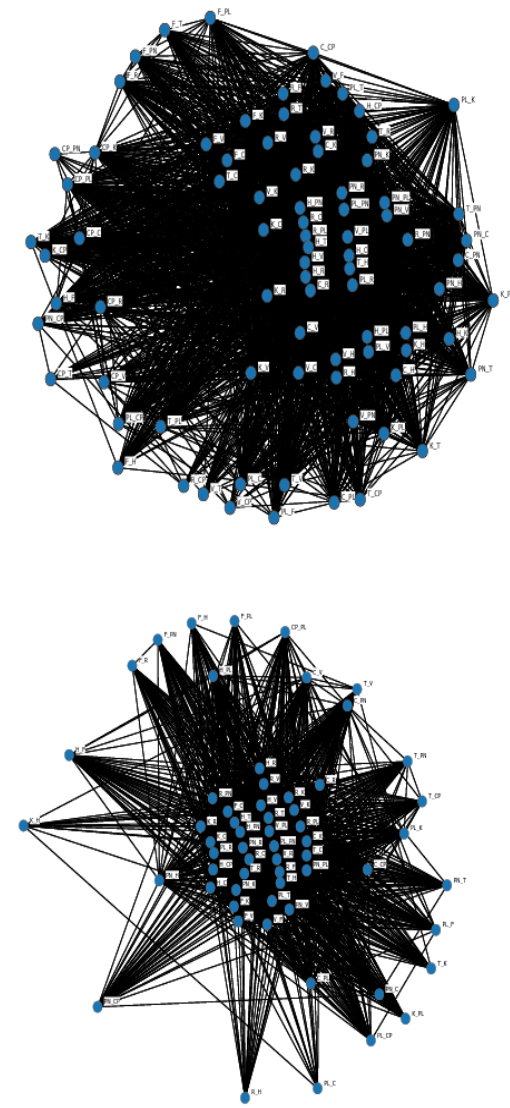

(a)
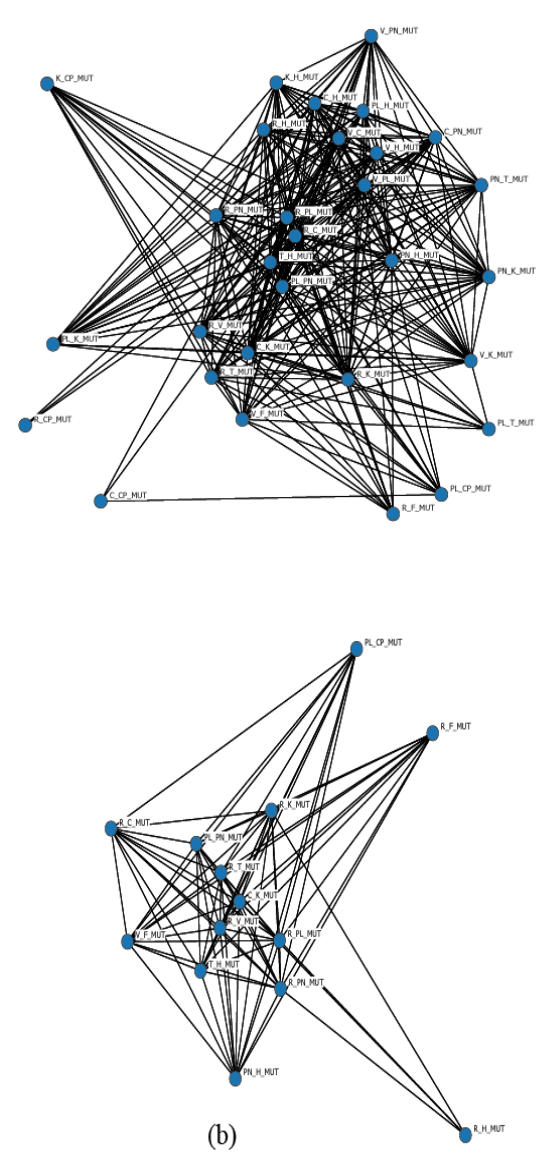

(b)
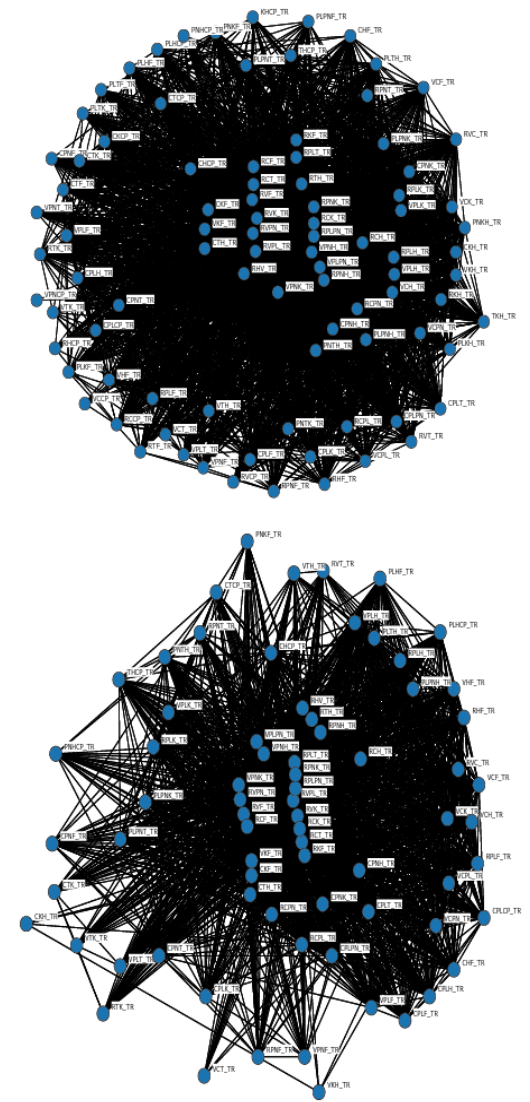

(c)
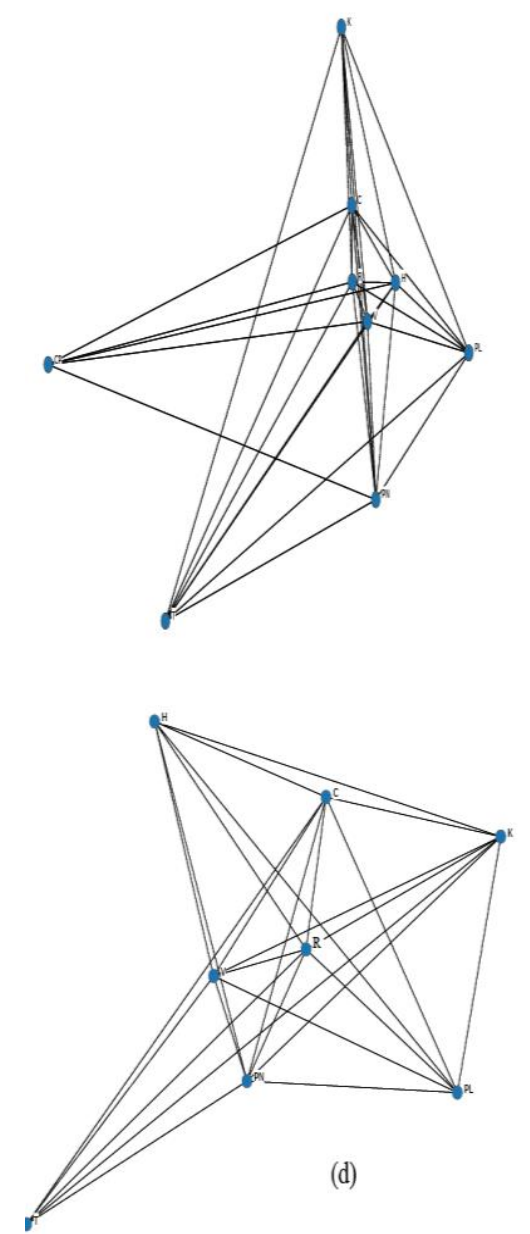

Fig. 8: Co-occurrence pattern of different types of resource interactions (RI) for all 140 farms (top) and farms of ninth decile of sustainability score (bottom). Co-occurrence patterns are - (a) Tie/linkage; (b) Reciprocal ties/linkage; (c) Triads; and (d) Presence in the Core. The proximity of RIs indicates the similarity of tie strength in a metric multi-dimensional layout of valued data. Nodes are moved minimally to make the labels legible. 
Farms at the highest decile of sustainability score, irrespective of their farm types, featured 35 cooccurring linkages, 11 cooccurring reciprocal linkages, 28 cooccurring triads, and presence of $\mathrm{R}, \mathrm{V}$, and PN at the core in terms of their high tie strengths (Row 3, Table 3). This means that these RIs are more closely linked and likely to cooccur on the same farm to achieve high farmsustainability. Notably, a high proportion of co-occurrences were retained by the highlysustainable farms of the highest decile. Finally, we identify 32 linkages, 11 reciprocal linkages, 22 triads, and three core elements (Row 4, Table 3) who occurred and cooccurred in the highly sustainable farms, and thus most critical to contribute towards the farm sustainability.

Table 3: Occurrence and co-occurrence of resource integrations patterns in the highly-sustainable farms

\begin{tabular}{|c|c|c|c|c|}
\hline & Linkages & Reciprocal & Triad & Presence at core \\
\hline $\begin{array}{l}\text { Farm resource } \\
\text { interactions } \\
\text { associated with } \\
\text { higher farm } \\
\text { sustainability (Fig. } \\
6 \text { ) }\end{array}$ & $\begin{array}{l}\text { R->PN, PN->PL, } \\
\text { PN->V, PL->PN, } \\
\text { PN->R, H->PN, K- } \\
>\mathrm{C}, \mathrm{V}->\mathrm{K}, \mathrm{R}->\mathrm{K}, \\
\mathrm{V}->\mathrm{PL}, \mathrm{PL}->\mathrm{R}, \mathrm{H}- \\
>\mathrm{C}, \mathrm{K}->\mathrm{R}, \mathrm{H}->\mathrm{V}, \\
\mathrm{C}->\mathrm{R}, \mathrm{H}->\mathrm{R}, \mathrm{T}->\mathrm{H}, \\
\mathrm{R}->\mathrm{C}, \mathrm{H}->\mathrm{T}, \mathrm{PN}- \\
>\mathrm{K}, \mathrm{T}->\mathrm{R}, \mathrm{V}->\mathrm{R}, \mathrm{C}- \\
>\mathrm{CP}, \mathrm{H}->\mathrm{CP}, \mathrm{PL}- \\
>\mathrm{T}, \mathrm{F}->\mathrm{V}, \mathrm{F}->\mathrm{K}, \mathrm{R}- \\
>\mathrm{T}, \mathrm{F}->\mathrm{C}, \mathrm{R}->\mathrm{F}, \mathrm{T}- \\
>\mathrm{C}, \mathrm{C}->\mathrm{K}, \mathrm{R}->\mathrm{V}\end{array}$ & $\begin{array}{l}\mathrm{V}<->\mathrm{F}, \mathrm{R}<->\mathrm{T}, \mathrm{R}<- \\
>\mathrm{V}, \mathrm{C}<->\mathrm{K}, \mathrm{R}<->\mathrm{K}, \\
\mathrm{T}<->\mathrm{H}, \mathrm{PL}<->\mathrm{PN}, \\
\mathrm{R}<->\mathrm{PN}, \mathrm{PN}<->\mathrm{H}, \\
\mathrm{R}<->\mathrm{PL}, \mathrm{R}<->\mathrm{C},\end{array}$ & $\begin{array}{l}\Delta \text { PL-PN-K, } \Delta \text { R-C- } \\
\mathrm{H}, \Delta \mathrm{R}-\mathrm{C}-\mathrm{K}, \Delta \mathrm{V}- \\
\mathrm{PN}-\mathrm{H}, \Delta \mathrm{R}-\mathrm{H}-\mathrm{V}, \\
\Delta \mathrm{R}-\mathrm{PN}-\mathrm{K}, \Delta \mathrm{V}-\mathrm{PN}- \\
\mathrm{K}, \Delta \mathrm{R}-\mathrm{PL}-\mathrm{PN}, \Delta \mathrm{V}- \\
\mathrm{PL}-\mathrm{PN}, \Delta \mathrm{R}-\mathrm{PN}-\mathrm{H}, \\
\Delta \mathrm{R}-\mathrm{T}-\mathrm{H}, \Delta \mathrm{R}-\mathrm{V}-\mathrm{K} \\
\Delta \mathrm{R}-\mathrm{V}-\mathrm{PL}, \Delta \mathrm{R}-\mathrm{V}- \\
\mathrm{PN}, \Delta \mathrm{C}-\mathrm{T}-\mathrm{H}, \Delta \mathrm{R}-\mathrm{K}- \\
\mathrm{F}, \Delta \mathrm{V}-\mathrm{K}-\mathrm{F}, \Delta \mathrm{R}-\mathrm{V}- \\
\mathrm{F}, \Delta \mathrm{R}-\mathrm{PL}-\mathrm{T}, \Delta \mathrm{C}-\mathrm{H}- \\
\mathrm{CP}, \Delta \mathrm{C}-\mathrm{K}-\mathrm{F}, \Delta \mathrm{R}-\mathrm{C}- \\
\mathrm{F}, \Delta \mathrm{R}-\mathrm{C}-\mathrm{T}\end{array}$ & $\mathrm{R}, \mathrm{C} ; \mathrm{V}, \mathrm{PN}$ \\
\hline $\begin{array}{l}\text { Occurrence of } \\
\text { resource interaction } \\
\text { leading to high } \\
\text { sustainability (ninth } \\
\text { decile) (Fig. 7) }\end{array}$ & $\begin{array}{l}\mathrm{V}->\mathrm{F}, \mathrm{F}->\mathrm{K}, \mathrm{PN}- \\
>\mathrm{V}, \mathrm{R}>\mathrm{C}, \mathrm{T}>\mathrm{H}, \\
\mathrm{H}>\mathrm{CP}, \mathrm{F}>\mathrm{V}, \mathrm{T}>\mathrm{R}, \\
\mathrm{PN}>\mathrm{PL}, \mathrm{PN}>\mathrm{K}, \\
\mathrm{PL}>\mathrm{T}, \mathrm{V}>\mathrm{R}, \mathrm{R}>\mathrm{F}, \\
\mathrm{PN}>\mathrm{R}, \mathrm{PN}>\mathrm{H}, \\
\mathrm{R}>\mathrm{PN}, \mathrm{T}>\mathrm{C}, \mathrm{PL}>\mathrm{R}, \\
\mathrm{C}>\mathrm{K}, \mathrm{V}>\mathrm{PL}, \mathrm{R}>\mathrm{T}, \\
\mathrm{R}>\mathrm{V}, \mathrm{K}>\mathrm{R}, \mathrm{F}>\mathrm{C}, \\
\mathrm{V}>\mathrm{K}, \mathrm{PL}>\mathrm{PN}, \mathrm{R}>\mathrm{K}, \\
\mathrm{K}>\mathrm{C}, \mathrm{H}>\mathrm{V}, \mathrm{H}>\mathrm{T}, \\
\mathrm{H}>\mathrm{PN}, \mathrm{R}>\mathrm{PL}, \mathrm{H}>\mathrm{C}, \\
\mathrm{C}>\mathrm{R}\end{array}$ & $\begin{array}{l}\mathrm{R}<->\mathrm{PN}, \mathrm{R}<->\mathrm{PL}, \\
\mathrm{C}<->\mathrm{K}, \mathrm{R}<->\mathrm{V}, \mathrm{R}<- \\
>\mathrm{T}, \mathrm{T}<->\mathrm{H}, \mathrm{PL}<- \\
>\mathrm{PN}, \mathrm{V}<->\mathrm{F}, \mathrm{R}<- \\
>\mathrm{K}, \mathrm{R}<->\mathrm{C}, \mathrm{PN}<- \\
>\mathrm{H}\end{array}$ & $\begin{array}{l}\Delta \mathrm{R}-\mathrm{PN}-\mathrm{H}, \Delta \mathrm{R}-\mathrm{T}-\mathrm{H}, \\
\Delta \mathrm{R}-\mathrm{PL}-\mathrm{PN}, \Delta \mathrm{R}-\mathrm{V}- \\
\mathrm{K}, \Delta \mathrm{V}-\mathrm{PN}-\mathrm{H}, \Delta \mathrm{R}- \\
\text { PN-K, } \Delta \mathrm{R}-\mathrm{V}-\mathrm{PN}, \\
\Delta \mathrm{V}-\mathrm{PL}-\mathrm{PN}, \Delta \mathrm{V}-\mathrm{PN}- \\
\mathrm{K}, \Delta \mathrm{R}-\mathrm{C}-\mathrm{K}, \Delta \mathrm{R}-\mathrm{C}- \\
\mathrm{T}, \Delta \mathrm{R}-\mathrm{V}-\mathrm{PL}, \Delta \mathrm{R}-\mathrm{V}- \\
\mathrm{F}, \Delta \mathrm{R}-\mathrm{PL}-\mathrm{T}, \Delta \mathrm{R}-\mathrm{C}- \\
\mathrm{F}, \Delta \mathrm{R}-\mathrm{K}-\mathrm{F}, \Delta \mathrm{V}-\mathrm{K}- \\
\mathrm{F}, \Delta \mathrm{C}-\mathrm{K}-\mathrm{F}, \Delta \mathrm{C}-\mathrm{T}- \\
\mathrm{H}, \Delta \mathrm{CH}-\mathrm{C}-\mathrm{P}, \Delta \mathrm{C}- \\
\mathrm{PN}-\mathrm{H}, \Delta \mathrm{C}-\mathrm{PL}-\mathrm{PN}, \\
\Delta \mathrm{C}-\mathrm{PN}-\mathrm{K}, \\
\Delta \mathrm{R}-\mathrm{C}-\mathrm{PL}, \Delta \mathrm{C}-\mathrm{PL}-\mathrm{T}, \\
\Delta \mathrm{R}-\mathrm{C}-\mathrm{PN}\end{array}$ & $\mathrm{R}, \mathrm{V}, \mathrm{C}, \mathrm{K}, \mathrm{PN}, \mathrm{PL}$ \\
\hline $\begin{array}{l}\text { Co-occurrence of } \\
\text { farm resource } \\
\text { interaction pattern } \\
\text { leading to higher } \\
\text { sustainability (ninth } \\
\text { decile) (Fig. 8) }\end{array}$ & $\begin{array}{l}\mathrm{K}->\mathrm{R}, \mathrm{K}->\mathrm{C}, \mathrm{PL}- \\
>\mathrm{R}, \mathrm{H}->\mathrm{CP}, \mathrm{H}->\mathrm{C}, \\
\mathrm{R}->\mathrm{PN}, \mathrm{F}->\mathrm{C}, \mathrm{H}- \\
>\mathrm{T}, \mathrm{H}->\mathrm{PN}, \mathrm{PN}->\mathrm{R}, \\
\mathrm{R}->\mathrm{C}, \mathrm{T}->\mathrm{R}, \mathrm{PN}- \\
>\mathrm{K}, \mathrm{F}->\mathrm{K}, \mathrm{F}->\mathrm{V}, \mathrm{H}- \\
>\mathrm{R}, \mathrm{R}->\mathrm{V}, \mathrm{H}->\mathrm{V}, \\
\mathrm{R}->\mathrm{T}, \mathrm{V}->\mathrm{PL}, \mathrm{PL}- \\
>\mathrm{PN}, \mathrm{V}->\mathrm{R}, \mathrm{R}->\mathrm{F}, \\
\mathrm{T}->\mathrm{H}, \mathrm{PL}->\mathrm{T}, \mathrm{PN}-\end{array}$ & $\begin{array}{l}\mathrm{R}<->\mathrm{K}, \mathrm{PL}<->\mathrm{PN}, \\
\mathrm{R}<->\mathrm{T}, \mathrm{C}<->\mathrm{K}, \mathrm{R}<- \\
>\mathrm{V}, \mathrm{T}<->\mathrm{H}, \mathrm{R}<- \\
>\mathrm{PL}, \mathrm{R}<->\mathrm{PN}, \\
\mathrm{PN}<->\mathrm{H}, \mathrm{V}<->\mathrm{F}, \\
\mathrm{R}<->\mathrm{C}\end{array}$ & $\begin{array}{l}\Delta \mathrm{R}-\mathrm{H}-\mathrm{V}, \Delta \mathrm{R}-\mathrm{T}-\mathrm{H}, \\
\Delta \mathrm{R}-\mathrm{PN}-\mathrm{H}, \Delta \mathrm{V}-\mathrm{PL}- \\
\text { PN, } \Delta \mathrm{V}-\mathrm{PN}-\mathrm{H}, \Delta \mathrm{R}- \\
\text { PL-T, } \Delta \mathrm{R}-\mathrm{PN}-\mathrm{K}, \\
\Delta \mathrm{R}-\mathrm{PL}-\mathrm{PN}, \Delta \mathrm{R}-\mathrm{V}- \\
\text { PL, } \Delta \mathrm{R}-\mathrm{V}-\mathrm{K}, \Delta \mathrm{R}-\mathrm{C}- \\
\mathrm{K}, \Delta \mathrm{R}-\mathrm{C}-\mathrm{T}, \Delta \mathrm{R}-\mathrm{K}- \\
\mathrm{F}, \Delta \mathrm{V}-\mathrm{PN}-\mathrm{K}, \Delta \mathrm{R}-\mathrm{V}- \\
\text { PN, } \Delta \mathrm{R}-\mathrm{V}-\mathrm{F}, \Delta \mathrm{R}-\mathrm{C}- \\
\mathrm{F}, \Delta \mathrm{V}-\mathrm{K}-\mathrm{F}, \Delta \mathrm{C}-\mathrm{K}-\end{array}$ & $\mathrm{R}, \mathrm{V}, \mathrm{PN}$ \\
\hline
\end{tabular}




\begin{tabular}{|c|c|c|c|}
\hline & $\begin{array}{l}>\mathrm{V}, \mathrm{V}->\mathrm{F}, \mathrm{R}->\mathrm{K} \\
\mathrm{V}->\mathrm{K}, \mathrm{R}->\mathrm{PL}, \mathrm{C}- \\
>\mathrm{K}, \mathrm{T}->\mathrm{C}, \mathrm{PN}->\mathrm{PL} \\
\mathrm{C}->\mathrm{R}\end{array}$ & & $\begin{array}{l}\mathrm{F}, \Delta \mathrm{C}-\mathrm{T}-\mathrm{H}, \Delta \mathrm{R}-\mathrm{C}- \\
\mathrm{PN}, \Delta \mathrm{C}-\mathrm{PN}-\mathrm{K}, \Delta \mathrm{C}- \\
\mathrm{PN}-\mathrm{H}\end{array}$ \\
\hline $\begin{array}{l}\text { Resource } \\
\text { interactions that } \\
\text { occurred and } \\
\text { cooccurred in the } \\
\text { farms of the highest } \\
\text { decile }\end{array}$ & $\begin{array}{l}\text { V->F, F->K, } \\
\text { PN->V, R->C, } \\
\text { T->H, H->CP, F- } \\
>\mathrm{V}, \mathrm{T}->\mathrm{R}, \mathrm{PN}->\mathrm{PL}, \\
\text { PN->K, PL->T, V- } \\
>\mathrm{PL}, \mathrm{R}->\mathrm{F}, \mathrm{PN}->\mathrm{R}, \\
\mathrm{R}->\mathrm{PN}, \mathrm{T}->\mathrm{C}, \mathrm{PL}- \\
>\mathrm{R}, \mathrm{C}->\mathrm{K}, \mathrm{V}->\mathrm{PL} \\
\mathrm{R}->\mathrm{T}, \mathrm{R}->\mathrm{V}, \mathrm{F}->\mathrm{C} \\
\mathrm{V}->\mathrm{K}, \mathrm{PL}->\mathrm{PN}, \mathrm{R}- \\
>\mathrm{K}, \mathrm{K}>\mathrm{C}, \mathrm{H}>\mathrm{V}, \\
\mathrm{H}>\mathrm{T}, \mathrm{H}->\mathrm{PN}, \mathrm{R}- \\
>\mathrm{PL}, \mathrm{H}->\mathrm{C}, \mathrm{C}->\mathrm{R}\end{array}$ & $\begin{array}{l}\mathrm{R}<->\mathrm{PL}, \mathrm{R}<->\mathrm{V}, \\
\mathrm{C}<->\mathrm{K}, \mathrm{R}<->\mathrm{T}, \mathrm{T}<- \\
>\mathrm{H}, \mathrm{R}<->\mathrm{C}, \mathrm{PL}<- \\
>\mathrm{PN}, \mathrm{PN}<->\mathrm{H}, \mathrm{R}<- \\
>\mathrm{K}, \mathrm{R}<->\mathrm{PN}, \mathrm{V}<- \\
>\mathrm{F}\end{array}$ & $\begin{array}{l}\Delta \mathrm{R}-\mathrm{PN}-\mathrm{H}, \Delta \mathrm{V}-\mathrm{PN}- \\
\mathrm{H}, \Delta \mathrm{V}-\mathrm{R}, \mathrm{R}-\mathrm{V}, \mathrm{PN}, \Delta \mathrm{V}- \\
\mathrm{PN}-\mathrm{K}, \Delta \mathrm{R}-\mathrm{PN}-\mathrm{K}, \\
\Delta \mathrm{R}-\mathrm{T}-\mathrm{H}, \Delta \mathrm{R}-\mathrm{C}-\mathrm{K}, \\
\Delta \mathrm{R}-\mathrm{PL}-\mathrm{T}, \Delta \mathrm{R}-\mathrm{K}-\mathrm{F}, \\
\Delta \mathrm{C}-\mathrm{K}-\mathrm{F}, \Delta \mathrm{C}-\mathrm{PN}-\mathrm{K}, \\
\Delta \mathrm{R}-\mathrm{C}-\mathrm{PN}, \Delta \mathrm{R}-\mathrm{PL}- \\
\mathrm{PN}, \Delta \mathrm{R}-\mathrm{V}-\mathrm{PN}, \Delta \mathrm{R}- \\
\mathrm{C}-\mathrm{K}, \Delta \mathrm{R}-\mathrm{V}-\mathrm{PL}, \Delta \mathrm{R}- \\
\mathrm{V}-\mathrm{K}, \Delta \mathrm{R}-\mathrm{C}-\mathrm{F}, \Delta \mathrm{R}- \\
\mathrm{V}-\mathrm{F}, \Delta \mathrm{R}-\mathrm{C}-\mathrm{T}, \Delta \mathrm{V}- \\
\mathrm{K}-\mathrm{F}, \Delta \mathrm{C}-\mathrm{T}-\mathrm{H}\end{array}$ \\
\hline
\end{tabular}

\section{Linking Farm Resource Interaction with Farm Sustainability using a Formal Model}

Once we understand the mechanism to achieve sustainability by employing RI, we want to explain farm sustainability through a formal model. We try to explain the sustainability of the sampled farms by properties of the farms' RI networks. We computed 11 network properties (Table 2) for all the farms' RI network and reduce their multicollinearity by extracting two principal components from them. These PCs, named 'connectedness' (PC1) and 'reciprocity and transitivity' (PC2), are used as the predictor variables for explaining the farm sustainability score. We find a model explaining $88.7 \%$ of the variance in farm sustainability scores. We used 12 models, and Fig. 9a represents an average of the three best-performing models in terms of their correlation value and relative error. We also examine how the model performs in different farm types (Fig. 9b), and find the linear correlation for the five farm types to be $80.9 \%, 71.5 \%, 63.8 \%$, $72.7 \%$, and $86 \%$. These findings imply that resource interaction within the farms, expressed in terms of their network properties, can alone explain the farm sustainability measured by 39 multidimensional indicators, and this holds significantly for all farm types. 


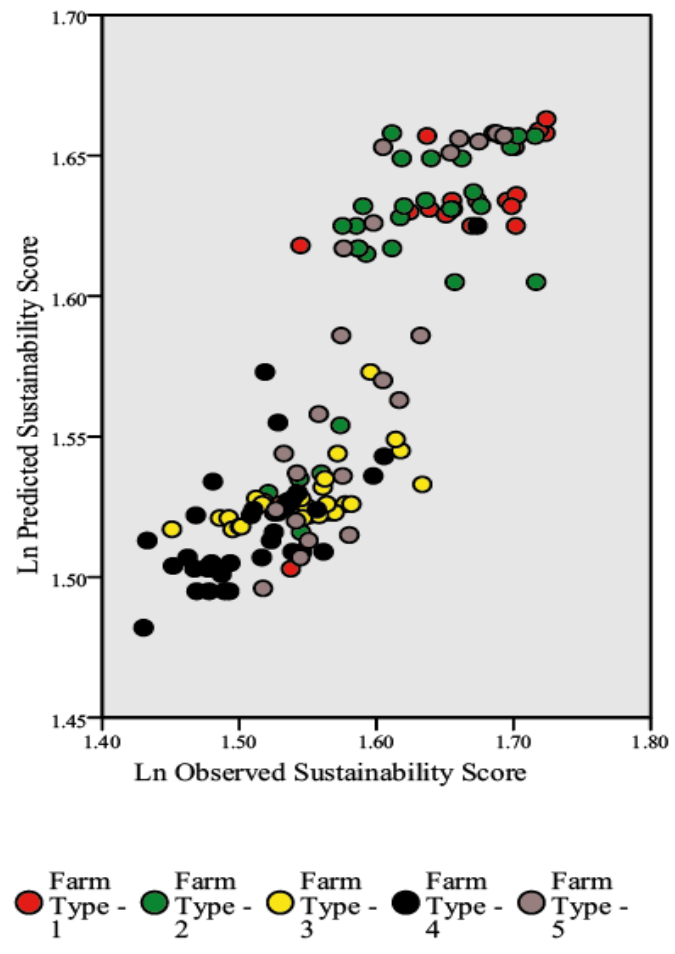

(a)

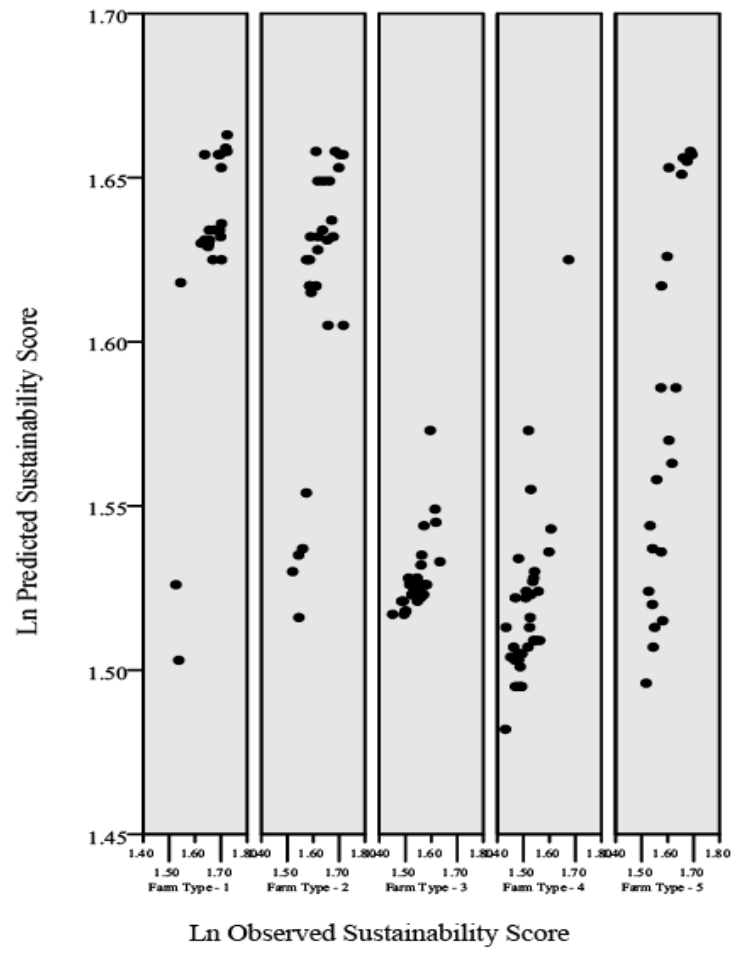

(b)

Fig. 9: Relationship between the observed and predicted value of sustainability score (a) for all farms taken together, and (b) for five farm types separately. Predictor variables are two principal components extracted from 11 network properties of farm resource interaction. The output is based on three best-performing models in terms of their correlation value and relative error.

We take the explanation a step ahead to examine the nature of this relationship at different values of PC1 and PC2 separately (Fig. 10). We find that farm sustainability increases monotonically with increased PC1 and find two areas of stacked points (farms) in the graph (Fig. 10a), which are roughly the boundary of $\mathrm{PC} 1$ for one or more group/s of farms. While the first stack is the boundary of PC1 for FT-3 and FT-4, the second stack is the boundary for all other farm types. This indicated that RI, in the form of increased connectedness, could not be advanced by those groups of farms beyond a specific limit, although differential sustainability was achieved by farms of the same type with that same level of connectedness. These boundaries suggest a resource-limiting condition for a large number of resource-poor farms. In Fig. 10b, we found that PC2 enhanced farm sustainability up to a point and declined after that. Here, also we find two stacks of farms - first, the highly-sustainable farms of FT-1, FT-2, and few farms from FT-5; second, the poorlysustainable farms of FT-3 and FT-4. We anticipate that highly-sustainable farms do not need to 
engage in many reciprocal and transitive RI on their farms because they could achieve substantial sustainability with singular connectedness and do not need to move further towards the right of the $\mathrm{x}$-axis. On the other hand, farms in the second stack have limited resources, mostly located close to each other and could be linked easily (that enhanced their reciprocity and transitivity). However, this could lift only a smaller proportion of farms above-median sustainability (Fig. 10b).

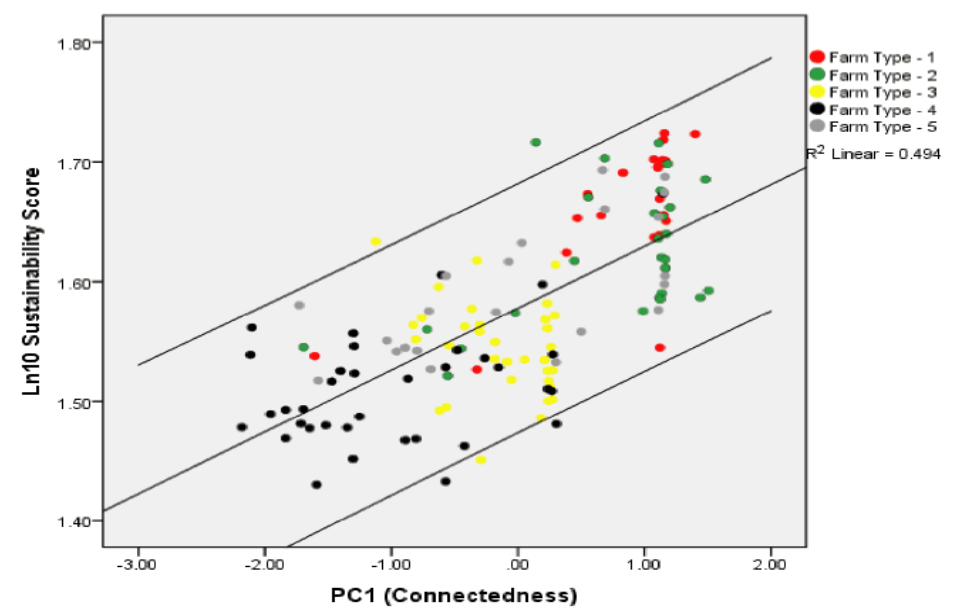

(a)

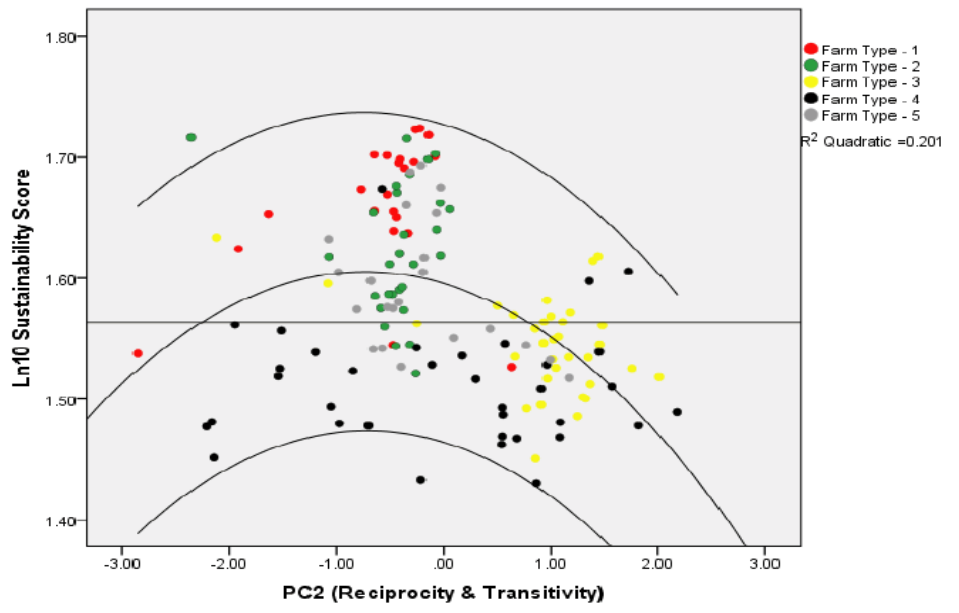

(b)

Fig. 10: Relationship between the principal components (PC) of network properties of resource interaction and farm sustainability for different farm types. Two PCs, namely PC1 (Connectedness) and PC2 (Reciprocity \& Transitivity) are extracted from 11 network properties, and sustainability score is measured by a composite index. (a) PC1 shows a linear, and (b) PC2 shows a non-linear relationship with farm sustainability score. Lines flanking the trendline is confidence intervals, and the horizontal line in $10 \mathrm{~b}$ is the median sustainability score 


\section{Discussion}

It is often debated that farm sustainability depends on farm size, although there exist diverse alternative arguments and perspectives (Woodhouse, 2010) and for our data set no such association was found between the two. Moreover, increase in the size of individually-owned farmland is unlikely to occur in most developing nations (Hazell \& Rahman, 2014), and it is pragmatic to find ways of achieving sustainability in these smaller parcels of land by using endogenous resources innovatively and efficiently. Parallel to this, there is evidence that suggests a limit to the agricultural intensification in densely-populated areas (Jayne et al., 2014). We try to understand what could happen to farm sustainability had we not intervened in them externally, and let them operate with their existing resources, practices, and technologies. We want to know what resource interactions are working well out there and for whom? We argue that farm types in the study regions have distinct characteristics, which have evolved over time; farm resources, along with their interactions, are one of the underlying basis and mechanism of such evolution (Chopin, Blazy, \& Dore, 2015). We tell a part of the story of farm sustainability in this article since farms do not sustain by resource interaction only. There is a limit beyond which resource interaction may not work and need external intervention to move to a different regime of sustainability (Tittonnell, 2014b). We show what 'rules of the game' (of resource interaction) operated in small farms, for whom, and how they could have translated into farm sustainability.

Farming systems undergo endogenous intensification as a response to land constraints (Boserup, 1965), often resulting in the present context of sustainable intensification. Most farms in FT-1 have not felt the pressure of unsustainability, probably due to the larger land size owned by joint extended family and substantial off-farm income that could support the family across seasons. On the other extreme, FT-4 had little physical resources and access to formal institutions to get themselves extricated out of unsustainability and a poverty trap. While FT-2 intensified their smaller lands and earned off-farm incomes to sustain their farm and livelihoods, FT-3 resorted to migration and received off-farm income in the form of remittance. FT-5 diversified and commercialized farming with little dependence on off-farm income. Hence, the Boserupean explanation of agricultural intensification as a response to increased pressure on resources holds partially true for FT-2 and FT-5. On the other hand, FT-3 demonstrates something close to a Malthusian explanation where farming is abandoned partially for earning off-farm incomes. 
Interestingly, apart from FT-5, all other FTs depended on off-farm income to sustain their farms and livelihoods. This trend of simultaneous intensification and resource integration in farms and migration are reported in the context of Africa (Demont et al., 2007). Similarly, the overarching importance of off-farm income (Fig. S3) suggests a need to further examine the role of off-farm income in shaping resource-use patterns and farm sustainability. Further, although there are dissimilarities between different farm types in terms of abundance of RI patterns (Fig. 5), we find only a few unique co-occurrences of RIs on the same farm. Interestingly, although the differences among FTs are quite diverse in terms of assets, practices, and outcomes, they differ subtly in terms of their combination of resource interactions on the same farm. This suggests that a group of farms can potentially be put on a different sustainability regime (that is a farm type) just by introducing a minimal number of, or combinations of, RIs in farming systems.

We find that particular occurrence (Fig. 7) and co-occurrence (Fig. 8) of RIs are associated with highly-sustainable farms. Now, this commonality of occurrence and co-occurrence of RIs gives us reasonable confidence to conclude that this common RIs are associated with the highly-sustainable farms and are also more likely to occur on the same farm. Our analyses have identified 35 discrete linkages, 11 reciprocal linkages, 28 triads, and three core components associated with higher sustainability of small-scale farms in the study area since they were associated with highlysustainable farms and at the same time cooccurred on the same farm. This conclusion is of crucial significance since we do not only claim a relationship between RI and farm sustainability but find different forms of discrete resource interaction patterns associated with farm sustainability. This is a direct entry point into the design of sustainable farming systems that avoids promotion of models that are either too burdensome to accept as such in an area and need significant logistic support and social mobilization to succeed in the long run. The results of our study suggest the importance of understanding the network phenomenon of resource interaction in small farms to achieve farm sustainability through informed technological intervention. Also, we could understand how different farm types engaged different RIs to achieve sustainability, indicating towards a typology-based intervention strategy. The analysis also reveals the importance of Ricebased integrations in farm sustainability of the study areas, followed by Vegetables and Pondbased integrations, suggesting precautionary and ex-ante assessment of impacts in farming systems before undertaking technological and policy interventions. 
In addition to finding that discrete resource interactions are associated with farm sustainability, we also found that the network properties of RIs can explain farm sustainability (Fig. 9), without having to include any socio-economic and biophysical variables in the model. This observation suggests the existence of a network phenomenon of RI on small-scale farms that link to farm sustainability. The linear relationship between 'connectedness' (PC1) in RIs and farm sustainability also suggests that higher resource integration can lead to higher farm sustainability. On the other hand, a non-linear relationship between 'transitivity and reciprocity' (PC2) and farm sustainability - where sustainability first increases and then declines - suggests a limit to which sustainability could be increased by enhancing reciprocal resource integration or extending the resource integration indefinitely. Considering the types of farms, it emerges that more sustainable farms (mostly FT-1 and FT-2) and less sustainable farms (FT-3 and FT-4) stack at a point of the $\mathrm{x}$-axis as if a sieve is stopping the farms from moving further ahead (Fig. 10). This suggests the limit of 'connectedness' (or singular integration) and 'transitivity and reciprocity' (or reciprocal and extended integration) with available farm resources.

Both sustainable and less-sustainable farms enhance sustainability by increasing RIs, but the lesssustainable farms may move ahead due to resource constraints (Fig. 10a) and increase reciprocal and extended integration to enhance sustainability (Fig. 10b). Already sustainable farms, most likely, do not move ahead with enhanced reciprocation and extension of RIs, perhaps because they achieve sustainability well before the saturation in the integration using all possible physical resources Alternatively, this observation also suggests that there are likely some costs to resource integration, perhaps in terms of labor and/or management complexity, that lead farms to stop once they attain a certain sustainability threshold. Less-sustainable farms continue to enhance reciprocal and extended linkages (instead of one-way linkages) but cannot enhance sustainability beyond a point. Literature also suggests that there is a limit to which such intensification takes place in densely populated areas (Willy, Muyanga, \& Jayne, 2019). This is very important to one of our fundamental rationales of the study - to optimize the use of existing physical resources to achieve farm sustainability. We understand that RI can contribute higher sustainability for resource-rich farms (with more lands/trees/livestock) and put them on a higher regime of farm sustainability; however, the smaller farms will need external support and innovation to get out of the unsustainability trap (Fig. S3). Also, sustainable farms have demonstrated a limit to sustainability 
which can be extended by introducing innovations and policy regulations that operate outside the scope of the farm resource use (such as marketing support, tax reforms). Further, despite the limit to achieve sustainability with enhanced resource integration, there remains considerable variation in the magnitude of sustainability within the same farm type, suggesting farm-specific refinements within the broader scope of typology-specific interventions.

\section{Conclusion}

Farm sustainability is often framed along a dichotomy of external input-driven farming and internally-sustained agroecological farming. While useful for comparing key differences, this dichotomy ignores the important observation that smallholder farms are typically distributed between these two extremes, and that they can change their nature over time. Moreover, wholesale adoption of more integrated and agroecologically informed models of farming is often dependent on region-specific details and exceptional social learning for mass popularization (Rosset, Sosa, Jaime, \& Lozano, 2011). The present study demonstrates a very different approach, more endogenous to farms themselves, by linking farm sustainability with the network properties of a farm's resource-use patterns. It also identifies discrete resource-interaction strategies that help farmers to achieve long-term sustainability. This work points the way to a more incremental path toward sustainability, in contrast to a wholesale transformation, which can be challenging for smallholder farms that may be risk-averse due to their already marginal socio-economic status. The results thus support the argument that the promotion of discrete resource interactions can move farms along the sustainability gradient more parsimoniously (Goswami et al., 2016).

We acknowledge that sustainability in small-scale farms cannot be improved indefinitely by creating new RIs on the farms, and there is a limit to such achievement for different farm types. We understand that feasible actions on a farm are often guided by a set of biophysical as well as socio-political realities that fundamentally guide and also constrain on-farm decision making. Ultimately, the capacity of farmers to achieve critical RIs must be understood within the broader framework of culture, power, and access to resources. Our analysis is not intended to side-step those broader issues, which fundamentally affect the success of agricultural development efforts worldwide, but to enrich our understanding of key elements of farm sustainability. 
This novel approach opens up the possibility to theorize farm sustainability as an outcome of the network phenomenon of resource utilization. It explains the structural bases of sustainability that could help in designing farming systems to achieve a set of desired outcomes. The analytical approach may be extended to study differential structures of RI networks in different agroecological regions and their evolutions in different contexts. Also, this can be used to improve the performance of agricultural research and extension through structural analysis and design of farming systems, and strategic technology targeting to achieve long-term sustainability in millions of small-scale farms.

\section{Acknowledgement}

Rupak Goswami was awarded with the Fulbright-Nehru Fellowship, provided by the United States-India Educational Foundation that allowed him to conduct this research.

\section{References}

Altieri, M. A. (1990). Agroecology: The Science of Sustainable Agriculture. Boca Raton, CRC Press.

Altieri, M. A. (2009). Agroecology, small farms, and food sovereignty. Monthly Review, 61(3), 102-113. https://doi.org/10.14452/mr-061-03-2009-07_8

Altieri, M. A., Funes-Monzote, F. R., \& Petersen, P. (2012). Agroecologically efficient agricultural systems for smallholder farmers: contributions to food sovereignty. Agronomy for Sustainable Development, 32(1), 1-13. https://doi.org/10.1007/s13593-011-0065-6

Apata, T. G., N'Guessan, Y. G., Ayantoye, K., Borokini, A., Okanlawon, M., Bamigboye, O., ... \& Busari, A. O. (2020). Doggedness of small farms and productivity among smallholder farmers in Nigeria: Empirical linkage and policy implications for poverty reduction. Business Strategy \& Development, 3(1), 128-142. https://doi.org/10.1002/bsd2.83

Basso, B., Liu, L., \& Ritchie, J. T. (2016). A comprehensive review of the CERES-wheat,-maize and-rice models' performances. In Advances in Agronomy (vol. 136, pp. 27-132). Academic Press. https://doi.org/10.1016/bs.agron.2015.11.004

Béné, Christophe (2020) Resilience of local food systems and links to food security - A review of some important concepts in the context of COVID-19 and other shocks. Food Security, volume 12, 805-822. https://doi.org/10.1007/s12571-020-01076-1. 
Bommarco, R., Kleijn, D., \& Potts, S. G. (2013). Ecological intensification: harnessing ecosystem services for food security. Trends in Ecology \& Evolution, 28(4), 230-238. https://doi.org/10.1016/j.tree.2012.10.012

Borgatti S (2002) Netdraw Network Visualization. Harvard, MA, Analytic Technologies.

Borgatti S.P., Everett, M.G., Freeman, L.C. (2002). UCINET 6 for Windows: Software for Social Network Analysis (Analytic Technologies, Harvard, MA).

Borgatti, S. P., Everett, M. G., \& Johnson, J. C. (2018). Analyzing Social Networks. London, Sage.

Borgatti, S.P., \& Everett, M.G. (2000). Models of core/periphery structures. Social Networks 21 375-395. https://doi.org/10.1016/S0378-8733(99)00019-2

Boserup, E. (1965). The Conditions of Agricultural Growth: The Economics of Agrarian Change Under Population Pressure. Aldine Publishing Company, Ithaca. USA and CATIE. Turrialba, Costa Rica.

Brunori, G., Avermaete, T., Bartolini, F., Brzezina, N., Grando, S., Marsden, T., Mathijs, E., Moragues-Faus, A. and Sonnino, R. (2020), "Small Farming and Food and Nutrition Security", Brunori, G. and Grando, S. (Ed.) Innovation for Sustainability (Research in Rural Sociology and Development, Vol. 25), Emerald Publishing Limited, pp. 19-38. https://doi.org/10.1108/S1057-192220200000025004

Cassman, K. G., \& Grassini, P. (2020). A global perspective on sustainable intensification research. Nature Sustainability, 3(4), 262-268. https://doi.org/10.1038/s41893-020-0507-8

Chopin, P., Blazy, J. M., \& Doré, T. (2015). A new method to assess farming system evolution at the landscape scale. Agronomy for Sustainable Development, 35(1), 325-337. https://doi.org/10.1007/s13593-014-0250-5

Collinson, M. P. (1987). Farming systems research: procedures for technology development. Experimental Agriculture, 23(4), 365-386. https://doi.org/10.1017/s0014479700017336

Collinson, M. P. (Ed.). (2000). A History of Farming Systems Research. CABI. https://doi.org/10.1079/9780851994055.0000

Cui, Z., Zhang, H., Chen, X., Zhang, C., Ma, W., Huang, C., ... \& Gao, Q. (2018). Pursuing sustainable productivity with millions of smallholder farmers. Nature, 555(7696), 363. https://doi.org/10. 1038/nature25785. 
Cumming, G. S., Buerkert, A., Hoffmann, E. M., Schlecht, E., von Cramon-Taubadel, S., \& Tscharntke, T. (2014). Implications of agricultural transitions and urbanization for ecosystem services. Nature, 515(7525), 50. https://doi.org/10.1038/nature13945.

De Haan, A. (1997). Migration as family strategy: rural-urban labor migration in India during the twentieth century. The History of the Family, 2(4), 481-505. https://doi.org/10.1016/s1081602x(97)90026-9.

Demont, M., Jouve, P., Stessens, J., \& Tollens, E. (2007). Boserup versus Malthus revisited: Evolution of farming systems in northern Côte d'Ivoire. Agricultural Systems, 93(1-3), 215228. https://doi.org/10.1016/j.agsy.2006.05.006.

Diaz-Balteiro, L., González-Pachón, J., \& Romero, C. (2017). Measuring systems sustainability with multi-criteria methods: A critical review. European Journal of Operational Research, 258(2), 607-616. https://doi.org/10.1016/j.ejor.2016.08.075.

Dunbar, R. I. M. (1989). Ecological modelling in an evolutionary context. Folia Primatologica, 53(1-4), 235-246. https://doi.org/10.1159/000156419.

Gajbhiye, K. S., \& Mandal, C. (2000). Agroecological zones, their soil resource and cropping systems. Status of Farm Mechanization in India, cropping systems, status of farm mechanization in India, 1-32. Irom http://el.doccentre.info/eldoc1/k30_/01jan00sfm1.pdf (accessed 12 April 2019)

Garnett, T., \& Godfray, C. (2012). Sustainable intensification in agriculture. Navigating a course through competing food system priorities. Food climate research network and the Oxford Martin programme on the future of food, University of Oxford, UK, 51. https://doi.org/10.1108/ijshe.2013.24914aaa.012

Gibson, R. B. (2006). Beyond the pillars: sustainability assessment as a framework for effective integration of social, economic and ecological considerations in significant decisionmaking. Journal of Environmental Assessment Policy and Management, 8(03), 259-280. https://doi.org/10.1142/s1464333206002517.

Gómez-Limón, J. A., \& Sanchez-Fernandez, G. (2010). Empirical evaluation of agricultural sustainability using composite indicators. Ecological Economics, 69(5), 1062-1075. https://doi.org/10.1016/j.ecolecon.2009.11.027. 
Goswami, R., Dasgupta, P., Saha, S., Venkatapuram, P., \& Nandi, S. (2016). Resource integration in smallholder farms for sustainable livelihoods in developing countries. Cogent Food \& Agriculture, 2(1), 1272151. https://doi.org/10.1080/23311932.2016.1272151.

Goswami, R., Saha, S., \& Dasgupta, P. (2017). Sustainability assessment of smallholder farms in developing countries. Agroecology and Sustainable Food Systems, 41(5), 546-569. https://doi.org/10.1080/21683565.2017.1290730.

Hall, A., Sulaiman, V. R., Clark, N., \& Yoganand, B. (2003). From measuring impact to learning institutional lessons: an innovation systems perspective on improving the management of international agricultural research. Agricultural Systems, 78(2), 213-241. https://doi.org/10.1016/s0308-521x(03)00127-6.

Hazell, P. (2011). Five big questions about five hundred million small farms. Rome: International Fund for Agricultural Development.

Hazell, P. B., \& Rahman, A. (Eds.). (2014). New directions for smallholder agriculture. OUP Oxford. https://doi.org/10.1093/acprof:oso/9780199689347.003.0001.

Hazell, P., Poulton, C., Wiggins, S., \& Dorward, A. (2010). The future of small farms: trajectories and policy priorities. World Development, 38(10), 1349-1361. https://doi.org/10.1016/j.worlddev.2009.06.012.

Hill, S. B. (1985). Redesigning the food system for sustainability. Alternatives, 12(3/4), 32-36.

Holzworth, D. P., Snow, V., Janssen, S., Athanasiadis, I. N., Donatelli, M., Hoogenboom, G., ... \& Thorburn, P. (2015). Agricultural production systems modelling and software: current status and future prospects. Environmental Modelling \& Software, 72, 276-286. https://doi.org/10.1016/j.envsoft.2014.12.013.

IBM_Corp (2016) IBM SPSS Modeler for Windows, Version 18.1. IBM Corp, Armonk, NY.

Jayne, T. S., Chamberlin, J., \& Headey, D. D. (2014). Land pressures, the evolution of farming systems, and development strategies in Africa: A synthesis. Food Policy, 48, 1-17. https://doi.org/10.1016/j.foodpol.2014.05.014.

Jones, J. W., Antle, J. M., Basso, B., Boote, K. J., Conant, R. T., Foster, I., ... \& Keating, B. A. (2017). Brief history of agricultural systems modeling. Agricultural systems, 155, 240-254. https://doi.org/10.1016/j.agsy.2016.05.014. 
Kansiime, M. K., van Asten, P., \& Sneyers, K. (2018). Farm diversity and resource use efficiency: Targeting agricultural policy interventions in East Africa farming systems. NJAS-Wageningen Journal of Life Sciences, 85, 32-41. https://doi.org/10.1016/j.njas.2017.12.001

Loos, J., Abson, D. J., Chappell, M. J., Hanspach, J., Mikulcak, F., Tichit, M., \& Fischer, J. (2014). Putting meaning back into "sustainable intensification". Frontiers in Ecology and the Environment, 12(6), 356-361. https://doi.org/10.1890/130157.

Martin, G., Moraine, M., Ryschawy, J., Magne, M. A., Asai, M., Sarthou, J. P., ... \& Therond, O. (2016). Crop-livestock integration beyond the farm level: a review. Agronomy for Sustainable Development, 36(3), 53. https://doi.org/10.1007/s13593-016-0390-x.

Musumba, M., Grabowski, P., Palm, C., \& Snapp, S. (2017). Sustainable Intensification Assessment Methods Manual (Working Draft). https://cgspace.cgiar.org/bitstream/handle/10568/90517/ftf_manual_oct2017.pdf?sequence=1 (Accessed 7 February 2019)

Netting, R. M. (1993). Smallholders, householders: farm families and the ecology of intensive, sustainable agriculture. Stanford, CA, Stanford University Press. doi:10.2307/2059541.

OECD. (2008). Handbook on constructing composite indicators: methodology and user guide. OECD publishing, Paris. https://doi.org/10.1787/9789264043466-en.

Pretty, J. N., Morison, J. I., \& Hine, R. E. (2003). Reducing food poverty by increasing agricultural sustainability in developing countries. Agriculture, Ecosystems \& Environment, 95(1), 217234. https://doi.org/10.1016/s0167-8809(02)00087-7.

Pretty, J., \& Bharucha, Z. P. (2014). Sustainable intensification in agricultural systems. Annals of Botany, 114(8), 1571-1596. https://doi.org/10.1093/aob/mcu205.

Pretty, J., Benton, T. G., Bharucha, Z. P., Dicks, L. V., Flora, C. B., Godfray, H. C. J., ... \& Pierzynski, G. (2018). Global assessment of agricultural system redesign for sustainable intensification. Nature Sustainability, 1(8), 441. https://doi.org/10.1038/s41893-018-0114-0.

Quayson, M., Bai, C. and Osei, V. (2020) Digital Inclusion for Resilient Post-COVID-19 Supply Chains: Smallholder Farmer Perspectives. IEEE Engineering Management Review, vol. 48 (3), 104-110, https://doi.org/10.1109/EMR.2020.3006259.

Rao, N. H., \& Rogers, P. P. (2006). Assessment of agricultural sustainability. Current Science, 91(4), 439-448. https://doi.org/10.2135/cropsci2006.0008br. 
Rockström, J., Williams, J., Daily, G., Noble, A., Matthews, N., Gordon, L., ... \& de Fraiture, C. (2017). Sustainable intensification of agriculture for human prosperity and global sustainability. Ambio, 46(1), 4-17. https://doi.org/10.1007/s13280-016-0793-6

Roling, N. and Engel, P. (1991). The Development of the Concept of the Agricultural Knowledge and Information System (AKIS): Implications for Extension. In: Rivera, W.M. and Gustafson, D.J. (eds.): Agricultural Extension. Amsterdam: Elsevier Science Publishers.

Rosset, P. M., Machín Sosa, B., Roque Jaime, A. M., \& Ávila Lozano, D. R. (2011). The Campesino-to-Campesino agroecology movement of ANAP in Cuba: social process methodology in the construction of sustainable peasant agriculture and food sovereignty. The Journal of Peasant Studies, 38(1), 161-191. https://doi.org/10.1080/03066150.2010.538584

Ruthenberg, H. (1980). Farming Systems in the Tropics (Third Edition), Oxford, UK, Clarendon Press.

Schut, M., Klerkx, L., Rodenburg, J., Kayeke, J., Hinnou, L. C., Raboanarielina, C. M., ... \& Bastiaans, L. (2015). RAAIS: Rapid Appraisal of Agricultural Innovation Systems (Part I). A diagnostic tool for integrated analysis of complex problems and innovation capacity. Agricultural Systems, 132, 1-11. https://doi.org/10.1016/j.agsy.2014.08.009

Scoones, I. (1998). Sustainable rural livelihoods: a framework for analysis. IDS Working Paper 72, Brighton, IDS. I. from https://opendocs.ids.ac.uk/opendocs/handle/20.500.12413/3390

Smith, E. A., \& Winterhalder, B. (2017). Natural selection and decision-making: Some fundamental principles. In Evolutionary ecology and human behaviour (pp. 25-60). London and New York, Routledge. https://doi.org/10.4324/9780203792704-2

Spielman, D. J., Davis, K., Negash, M., \& Ayele, G. (2011). Rural innovation systems and networks: findings from a study of Ethiopian smallholders. Agriculture and Human Values, 28(2), 195-212. https://doi.org/10.1007/s10460-010-9273-y

Stephens, E. C., Martin, G., van Wijk, M., Timsina, J., \& Snow, V. (2020). Impacts of COVID-19 on agricultural and food systems worldwide and on progress to the sustainable development goals. Agricultural Systems, 183, 102873. https://doi.org/10.1016/j.agsy.2020.102873 
Temel, T., Janssen, W., \& Karimov, F. (2003). Systems analysis by graph theoretical techniques: assessment of the agricultural innovation system of Azerbaijan. Agricultural Systems, 77(2), 91-116. https://doi.org/10.1016/s0308-521x(02)00087-2

Tilman, D., Balzer, C., Hill, J., \& Befort, B. L. (2011). Global food demand and the sustainable intensification of agriculture. Proceedings of the National Academy of Sciences, 108(50), 20260-20264. https://doi.org/10.1073/pnas.1116437108

Tittonell, P. (2014a). Ecological intensification of agriculture-sustainable by nature. Current Opinion in Environmental Sustainability, $\quad 8, \quad$ 53-61. https://doi.org/10.1016/j.cosust.2014.08.006

Tittonell, P. (2014b). Livelihood strategies, resilience and transformability in African agroecosystems. Agricultural Systems, 126, 3-14. https://doi.org/10.1016/j.agsy.2013.10.010

Tittonell, P., \& Giller, K. E. (2013). When yield gaps are poverty traps: The paradigm of ecological intensification in African smallholder agriculture. Field Crops Research, 143, 76-90. https://doi.org/10.1016/j.fcr.2012.10.007

Tittonell, P., Muriuki, A., Shepherd, K. D., Mugendi, D., Kaizzi, K. C., Okeyo, J., Velchot, L., Coe, R. \& Vanlauwe, B. (2010). The diversity of rural livelihoods and their influence on soil fertility in agricultural systems of East Africa-A typology of smallholder farms. Agricultural Systems, 103(2), 83-97. https://doi.org/10.1016/j.agsy.2009.10.001

Tittonell, P., Vanlauwe, B., Leffelaar, P. A., Rowe, E. C., \& Giller, K. E. (2005). Exploring diversity in soil fertility management of smallholder farms in western Kenya: I. Heterogeneity at region and farm scale. Agriculture, Ecosystems \& Environment, 110(3-4), 149-165. https://doi.org/10.1016/j.agee.2005.04.001

Wezel, A., Casagrande, M., Celette, F., Vian, J. F., Ferrer, A., \& Peigné, J. (2014). Agroecological practices for sustainable agriculture. A review. Agronomy for Sustainable Development, 34(1), 1-20. https://doi.org/10.1007/s13593-013-0180-7

Willy, D. K., Muyanga, M., \& Jayne, T. (2019). Can economic and environmental benefits associated with agricultural intensification be sustained at high population densities? A farm level empirical analysis. Land use policy, 81, 100-110. https://doi.org/10.1016/j.landusepol.2018.10.046 
Woodhouse, P. (2010). Beyond industrial agriculture? Some questions about farm size, productivity and sustainability. Journal of Agrarian Change, 10(3), 437-453. https://doi.org/10.1111/j.1471-0366.2010.00278.x

World Bank (2014) Building resilience for sustainable development of the Sundarbans. Strategy Report No. 88061-IN. Washington DC, The World Bank. 